\title{
Review Article \\ On the Environmental Factors Affecting the Structural and Cytotoxic Properties of IAPP Peptides
}

\author{
Marianna Flora Tomasello, ${ }^{1}$ Alessandro Sinopoli, ${ }^{2}$ and Giuseppe Pappalardo' \\ ${ }^{1}$ CNR Institute of Biostructures and Bioimaging, Via P. Gaifami 18, 95126 Catania, Italy \\ ${ }^{2}$ International PhD Program in Translational Biomedicine, University of Catania, Viale A. Doria 6, 95125 Catania, Italy \\ Correspondence should be addressed to Giuseppe Pappalardo; giuseppe.pappalardo@cnr.it
}

Received 27 November 2014; Accepted 5 February 2015

Academic Editor: Andrew Miranker

Copyright (c) 2015 Marianna Flora Tomasello et al. This is an open access article distributed under the Creative Commons Attribution License, which permits unrestricted use, distribution, and reproduction in any medium, provided the original work is properly cited.

\begin{abstract}
Pancreatic islets in type 2 diabetes mellitus (T2DM) patients are characterized by reduced $\beta$-cells mass and diffuse extracellular amyloidosis. Amyloid deposition involves the islet amyloid polypeptide (IAPP), a neuropancreatic hormone cosecreted with insulin by $\beta$-cells. IAPP is physiologically involved in glucose homeostasis, but it may turn toxic to $\beta$-cells owing to its tendency to misfold giving rise to oligomers and fibrils. The process by which the unfolded IAPP starts to self-assemble and the overall factors promoting this conversion are poorly understood. Other open questions are related to the nature of the IAPP toxic species and how exactly $\beta$-cells die. Over the last decades, there has been growing consensus about the notion that early molecular assemblies, notably small hIAPP oligomers, are the culprit of $\beta$-cells decline. Numerous environmental factors might affect the conformational, aggregation, and cytotoxic properties of IAPP. Herein we review recent progress in the field, focusing on the influences that membranes, $\mathrm{pH}$, and metal ions may have on the conformational conversion and cytotoxicity of full-length IAPP as well as peptide fragments thereof. Current theories proposed for the mechanisms of toxicity will be also summarized together with an outline of the underlying molecular links between IAPP and amyloid beta $(\mathrm{A} \beta)$ misfolding.
\end{abstract}

\section{Introduction}

Diabetes is a complex metabolic disorder characterized by chronic hyperglycemia and associated with macrovascular and microvascular complications [1]. It is estimated that the total number of people with diabetes will rise from 171 million in 2000 to 366 million in 2030 [2]. The two major forms of diabetes, classified by aetiology, are type 1 diabetes, which is characterized by an absolute deficiency in insulin resulting from autoimmune destruction of pancreatic $\beta$-cells, and type 2 diabetes which features combinations of decreased insulin secretion and insulin resistance. Type 2 diabetes mellitus (T2DM) accounts for about $90 \%$ of all the diabetes cases [1], and amyloid deposits are present in the pancreas of almost 90\% of T2DM patients [3-5]. These amyloid deposits are primarily composed of a protein called the islet amyloid polypeptide (IAPP) or amylin [6]. The strong correlation between amyloid fibril formation and $\beta$-cell death indicates the possible contribution of islet amyloidosis in the increase of $\beta$-cell failure in T2DM. IAPP is a member of the calcitonin like family of polypeptide and it is synthesized as an 89residue preprohormone. Removal of the 22-residue signal sequence leads to the 67-residue pro-IAPP, which is then processed in the Golgi and in the insulin secretory granule to give the 37-residue mature hormone [7, 8]. Additional posttranslational modifications include formation of an intramolecular disulfide bridge between residues 2 and 7 and amidation of the C-terminus. Mature IAPP is stored within the insulin secretory granules at a ratio of $1: 50$ to $1: 100$ relative to insulin and is cosecreted with insulin [9].

The physiological roles of IAPP are receptor mediated. The IAPP receptor is formed by a complex of the calcitonin receptor with a receptor activity modifying protein (RAMP) $[10,11]$. IAPP binds the calcitonin receptor (CTR) in the absence of RAMPs, but the affinity is rather low. 
The affinity of IAPP for the CTR-RAMP complex is higher, with an IC50 reported to be in the order of $8 \mathrm{nM}$ for the CTR-RAMP-1 complex [12].

Circulating concentrations of IAPP have been reported to range between 3 and 5 picomolars in rats, rising to 15-20 picomolars with increased blood glucose levels [13]. However these values are unlikely to be relevant to amyloid formation since IAPP is stored at a much higher level in the insulin secretory granule, between 500 micromolars and several millimolars. This implies that the local concentration of IAPP after being released from the granule will be temporarily much higher than the circulating concentration. The normal physiological roles of IAPP are not completely understood in humans, but studies in rodent models show that IAPP is involved in the suppression of satiety and adiposity, as well as the regulation of glucose homeostasis, gastric emptying, suppression of glucagon release, vasodilatation, and the excretion of calcium, potassium, and sodium [13-21]. IAPP's effect appears to take place mainly within the area postrema (AP) in the CNS. Several works provide a critical examination of the physiological roles of IAPP [13-15, 20-22] but this will not be discussed in this review.

IAPP is phylogenetically well preserved and found in all mammals, but not all species form amyloids [23-25]. Mice and rats do not develop islet amyloids, but cats, nonhuman primates, and humans do. The human polypeptide is amyloidogenic in vitro, while the rat IAPP (rIAPP) is not, even though the two polypeptides differ at only six positions located in the region 18-29. Notably, rIAPP contains three proline residues within the 20-29 sequence and these are believed to be responsible for its inability to form amyloid. Much attention has been focused on the sequence within the 20-29 region and the role it plays in controlling amyloid formation. This portion of the polypeptide chain is considered to be one of the major determinants of the ability of IAPP variants to form amyloid [26-28].

While there is a strong correlation between the primary sequence of the 20-29 segment and in vitro amyloidogenicity, mutations outside of this region can eliminate amyloid formation, indicating that it cannot be the sole factor controlling IAPP's amyloidogenicity [29-31]. Moreover there is recent evidence that the nonamyloidogenic rIAPP peptide is endowed with toxicity toward $\beta$-cell cultures as well $[32,33]$.

In the present review we summarize recent progress in the field focusing on the influences of membranes, $\mathrm{pH}$, and metal ions on the aggregation and cytotoxicity of IAPP and related peptide fragments. The current theories proposed for the mechanisms of toxicity will be also illustrated together with a brief account of the molecular links between hIAPP and amyloid beta $(\mathrm{A} \beta)$ misfolding.

\section{Environmental Conditions Affecting IAPP's Aggregation Process}

2.1. Amyloidogenic Properties of hIAPP. The connection between amyloidogenic proteins and disease was initially attributed to the amyloid form of the protein; however, increasing evidence suggests that the toxicity is due to intermediates generated during the assembly of amyloid fibers.
hIAPP amyloid deposits have a characteristic structure shared with other aggregates that commonly occur in Alzheimer's, Huntington's, Parkinson's, and other degenerative diseases. These amyloid aggregates are defined by their primarily $\beta$-sheet structure and their supramolecular organization into long fibers with the protein backbone orthogonal to the fiber axis [5].

Besides these structural characteristics, amyloids share common physical properties such as the general mechanism of assembly despite the lack of sequence similarity between the individual proteins. Amyloids are formed through a nucleation dependent process. This leads to characteristic sigmoidal type kinetics in which fibril formation is minimal (the lag-phase) until a critical concentration of nuclei (oligomers) is reached, at which point fibrils growth proceeds exponentially. The kinetic of assembly is typically intricate and involves a variety of on- and off-pathway intermediates found among all amyloidogenic proteins [34, and references cited therein]. Different aggregation profiles can be observed when solutions of fibrillogenic peptides contain prenucleated seeds of aggregates. In vitro, the seeding of amyloid proteins solutions with preformed fibrils leads to dramatically faster fibril growth [35]. In fact when seeds are present or added to hIAPP preparations the kinetic profiles of aggregation show extremely short lag phases.

hIAPP fibrils are stable structures not easily degraded by proteases. Generally harsh conditions, such as the use of concentrated formic acid or organic solvents, are needed to obtain their depolymerization [36]. The stability of amyloid fibrils makes them easy to handle and has prompted scientists to study them.

On the contrary, the study of the monomeric and oligomeric structures of hIAPP in physiological buffers has been troubled by their instability and fast "spontaneous" aggregation of the species. The most recent and most detailed model for the structure of hIAPP fibrils suggests that they are composed of stacked layers of two symmetric hIAPP molecules. These molecules form a parallel $\beta$-sheet structure running perpendicular to the length axis of the fibril [37]. Residues 8-17 and 28-37 form the $\beta$-sheet structure with a loop region located between them, whereas residues 1-7 are largely unstructured. Another model of the hIAPP fibril suggests that the fibril is composed of three protofilaments, each based on stacking of single hIAPP molecules in which residues 937 participate in a planar $S$ shaped fold forming the $\beta$-sheet structure $[38,39]$.

\subsection{Interaction with Membranes and Membrane Mimick-} ing Environment. Substantial evidence indicates that the membrane-mediated aggregation and subsequent deposition of hIAPP are linked to the dysfunction and death of pancreatic $\beta$-cells, but the molecular mechanisms of hIAPP deposition are poorly understood.

Many in vitro studies have shown that early oligomers of hIAPP formed during the aggregation process are the principal cytotoxic species and their toxicity is exerted through interactions with cell membranes. However many different hypotheses have been reported $[39,40]$. 
Two general theories exploring membrane disruption by hIAPP or other amyloid proteins have been proposed to date, even though the mechanisms are not exclusive and both may be operative at the same time. The first, known as the "pore theory," suggests that amyloid proteins form discrete pores within the membrane, either through a traditional ion channel type ("barrel stave") or in localized ruptures of the membrane that resemble discrete pores in some respects $[34,41]$.

In fact hIAPP has been found to increase the conductance of planar phospholipid bilayers [40]. The second theory suggests that the cause of membrane permeabilization and cytotoxicity might be not a specific (oligomeric) hIAPP species, but rather the process of hIAPP fibril growth at the membrane [39]. It was found that the assembly of hIAPP fibrils at the membrane causes membrane disruption, possibly by forcing the curvature of the bilayer to unfavourable angles or by the uptake of lipids by hIAPP fibrils during fibril elongation at the membrane [39].

$\beta$-cells contain $2.5-13.2 \mathrm{~mol} \%$ of anionic lipids and raft components (cholesterol and sphingomyelin) [40-46]. Thus, studies using model membrane surfaces mimicking the in vivo environment are useful for the understanding of amyloid deposition by hIAPP and for the development of effective therapeutically strategies [47]. Recent studies have demonstrated that cholesterol and lipid rafts content may affect the membrane driven aggregation of hIAPP and its accumulation on them [40-49]. Interestingly some lipids, particularly raft components, have been shown to be incorporated into amyloid deposits extracted from patients tissues affected with various amyloid diseases, including T2DM [40, 50]. The presence of phospholipid bilayers can reduce the lag-phase of hIAPP fibril formation, an effect that is most pronounced with negatively charged lipids. Since hIAPP has several positively charged residues, all of which are located at the $\mathrm{N}$-terminal side of the peptide, it has been thought that this region might be involved in the initial interaction of hIAPP with lipids, namely, with negatively charged lipids. In fact it has been shown that membrane binding of hIAPP is most efficient when bilayer lipids are negatively charged [39].

The N-terminal part of hIAPP, whilst not significantly involved in hIAPP fibril growth, was proposed to be important in the light of hIAPP membrane interactions [51-53]. However, we found that the hIAPP 17-29 peptide, lacking the $\mathrm{N}$-terminal part of hIAPP, was cytotoxic and was internalized in the mitochondrial compartment of RIN-5M cells [33]. Finally, similar to hIAPP, rIAPP can cause membranes to become permeable and cause cell toxicity, but it does not form amyloid [33, 54].

It is suggested that a transient membrane-bound $\alpha$-helical structure of hIAPP might play an important role in IAPP fibrillation in vivo. This is probably because of the exposure of the 20-29 region to an aqueous environment [55, 56], even if it has been shown that the region 20-29 can interact with membrane models without affecting their integrity [57]. The exposure of this amyloidogenic region facilitates amyloid nucleation by enhancing the orientation and increasing local concentration of the peptide. This suggests that a complex interplay between the helical intermediates and membranes is involved in the membrane-mediated aggregation of hIAPP and influenced by the peptide concentration and lipid composition [39, 40, 58, 59].

Support to the importance of the helix intermediate on IAPP aggregations is given by the effect of helix-inducing solvent HFIP on aggregation. A low percentage of HFIP (1\%) has a strong catalytic effect on aggregation while higher percentages trap the protein in a helical monomeric state $[34,39]$.

Since low percentage of HFIP affects the aggregation process it is important prior to starting any biophysical or biological measurements to exclude any trace of HFIP from the sample solution.

For these reasons it becomes important to adopt suitable procedures for sample preparation in order to achieve reproducible results [33].

2.3. $p H$ Influence on the Conformational Polymorphism of $I A P P$. Fibrillization involves the conversion of soluble random coil, $\alpha$-helical or $\beta$-sheet conformations into insoluble, aggregated $\beta$-pleated sheet structures. The conformational changes of IAPP are high conditional and even slight changes in parameters, such as $\mathrm{pH}$, peptide concentration, presence of preformed seeds, or metal ions concentration, may lead to different forms of aggregates that can be either fibrillar or amorphous.

As reported above, hIAPP is stored at extremely high concentrations in the secretory granules of pancreatic $\beta$-cells [31], together with insulin and in the presence of high zinc concentration and an acidic environment ( $\mathrm{pH}$ of 5.5). These conditions all together inhibit hIAPP aggregation and protect cells [60-63].

Conversely, the physiological pH of 7.4 for the extracellular matrix, into which amylin is secreted as the mature active hormone, favors fibril formation [63].

Amylin is a relatively simple system for the study of the effects of $\mathrm{pH}$ on fibrillization, because it has only two ionizable groups near neutrality, the $\alpha$-amino group at the $\mathrm{N}$ terminus and His18, because the C-terminus is naturally amidated in the mature hormone and it does not titrate with $\mathrm{pH}$ $[62,63]$.

It has been shown that protonation of the $\alpha$-amino group leads to a relatively modest inhibition of fibrillization; this slight effect of the $\alpha$-amino group is consistent with its location in a disordered part of the amylin fibril structure model [63]. Ionization of His18, which is part of the intermolecular $\beta$-sheet of amylin fibrils, causes a stronger inhibition of fibrillation as shown in different works. This is due to electrostatic repulsion between His18 stacked along the fibril axis $[62,63]$. As a matter of fact, at higher $\mathrm{pH}$ the peptide readily aggregates to form amyloid $[33,64]$.

While the effect of $\mathrm{pH}$ on the morphology of the hIAPP aggregates has been reported by several groups $[62,63,65$, $66]$, the effect of $\mathrm{pH}$ on hIAPP toxicity cannot be determined directly in cell cultures and the only data so far available has been obtained by using H18R hIAPP mutants to simulate the effect of pH. Generally speaking, decreased cytotoxicity was observed when a permanently charged arginine is substituted for the histidine at position 18 in agreement with 
the amorphous nature of the IAPP aggregates formed at low $\mathrm{pH}$ values $[62,63]$.

Literature work on IAPP's aggregation process focuses also on biophysical studies on IAPP related shorter sequences, derived from fibrillogenic regions of the full length parent peptide. Among these, the hIAPP17-29 peptide has been proposed as a useful model able to reproduce some of the key features of the whole hIAPP1-37 [64, 67]. In particular the $\mathrm{pH}$ dependence of fibrillization was maintained by the hIAPP17-29 peptide because of the presence of the His residue that is the only aminoacid residue that can be titrated over the $\mathrm{pH}$ range that hIAPP can experience in vivo [62].

2.4. IAPP Interaction with Transition Metal Ions. Metals ions, notably $\mathrm{Cu}(\mathrm{II})$ and $\mathrm{Zn}(\mathrm{II})$, and metal ions dyshomeostasis have been linked to the progression of several pathologies, including Alzheimer's and T2DM diseases [68], as their presence has been found in amyloid deposits characteristic of the above mentioned pathologies. $\mathrm{Cu}$ (II) is known to interact with numerous proteins and enzymes and is required for normal cellular functioning [69]. However, uncomplexed $\mathrm{Cu}$ (II) may be very hazardous, particularly under reducing environments, such as the cytosolic compartment, where $\mathrm{Cu}(\mathrm{II})$ is readily converted into the potent and reactive $\mathrm{Cu}(\mathrm{I})$ ion known to produce tissue damaging ROS. Many plaqueforming proteins including $\beta$-amyloid and prions were found to interact with copper, affecting the redox cycle of the metal to generate ROS in vitro [70-72]. The presence of copper in amyloid deposits and the alterations in its levels observed in various biofluids and tissues of individuals suffering T2DM $[73,74]$ have promoted investigations on the effect of $\mathrm{Cu}$ (II) on hIAPP aggregation. Nonetheless the role played by the $\mathrm{Cu}(\mathrm{II})$-hIAPP interaction in both aggregation and $\beta$-cell toxicity is still controversial. The majority of the studies dealing with the significance of $\mathrm{Cu}$ (II) and IAPP interactions emphasized the formation of $\mathrm{H}_{2} \mathrm{O}_{2}$ by human IAPP in vitro, the production of which is modestly elevated in the presence of $\mathrm{Cu}$ (II) $[75,76]$. Remarkably, copper-dependent generation of $\mathrm{H}_{2} \mathrm{O}_{2}$ was found to directly contribute to the toxicity of the $\beta$-amyloid peptide in primary neuronal cell cultures [77]. A very recent paper reports on a clear interaction mechanism of $\mathrm{Cu}(\mathrm{II})$ and hIAPP in pancreatic $\beta$-cells as copper compounds increased hIAPP-induced cytotoxicity by facilitating the apoptotic effect of hIAPP. Furthermore, $\mathrm{Cu}$ (II) promoted ROS overproduction and mitochondrial disruption which might be the main reason for the enhanced apoptosis [78]. Previous studies on complex formation between $\mathrm{Cu}$ (II) and two other common amyloid proteins, that is, $\beta$-amyloid and prions, were consistent with these findings. It has been reported that, similar to human amylin, these two misfolded proteins form $\mathrm{Cu}$ (II) complexes with physiologically relevant affinities. Chelation of $\mathrm{Cu}$ (II) by these two amyloids greatly diminished the production of ROS by $\mathrm{Cu}(\mathrm{II})$ and reduced their toxicity, which further corroborates the hypothesis that hIAPP/Cu(II) complex may have a protective role in cells $[79,80]$. Other authors reported that $\mathrm{Cu}(\mathrm{II})$ protects pancreatic $\beta$-cells from IAPP toxicity by increasing the activation energy needed for IAPP aggregation and by inhibiting IAPPinduced stress-kinase activation and signalling. Interestingly, the interaction of $\mathrm{Cu}$ (II) with hIAPP works as an antioxidant in cells rather than prooxidant activity as observed in vitro. This study further shows that both the hIAPP-induced ROS generation and the hIAPP-dependent activation of stress kinases (JNK) and caspases were blocked by preincubating hIAPP with $\mathrm{Cu}(\mathrm{II})$ [81].

Determinations of hIAPP fibrillization with ThT, AFM, and $\mathrm{EM}$ have revealed that $\mathrm{Cu}$ (II) inhibits the formation of mature hIAPP fibrils [82]. However, while some studies have shown that the copper-dependent decrease of hIAPP fibrillization was associated with the reduced hIAPP toxicity [81], others have pointed out that the copper-hIAPP interaction would increase hIAPP toxicity favouring the formation of toxic oligomers rather than inert fibrils. In fact, when supplied along with freshly dissolved hIAPP, $\mathrm{Cu}$ (II) decreased INS-1 rat insulinoma cell viability to a greater extent than what was observed in cells incubated with hIAPP alone [83]. In this case copper-induced oxidative stress was ruled out as the cause of toxicity, which was instead imputable to the inhibition of fibril formation and stabilization of toxic oligomeric forms. In fact it was demonstrated that $\mathrm{Ni}$ (II), which has similar binding preference as $\mathrm{Cu}$ (II) but forms non-redox-active complexes, also decreased both hIAPP fibril formation and increased hIAPP-related toxicity. Therefore, in the case of $\mathrm{Cu}$ (II), a decrease in amyloid formation does not correspond to a decrease in toxicity as $\mathrm{Cu}$ (II) possibly stabilizes either a toxic intermediate species of hIAPP or a toxic oligomerization-driven process.

Conformational changes can also explain the highest level of toxicity that has been observed after cell culture treatment with the hIAPP 17-29 fragment preincubated in the presence of $\mathrm{Cu}(\mathrm{II})$ and the absence of effects of copper on hIAPP1-37 spontaneous evolution towards toxic species [84]. Moreover, the observation that the rIAPP(17-29) peptide fragment can interact with copper(II) at physiological $\mathrm{pH}$ values, notwithstanding the lack of any common strongly coordination donor function, is noteworthy and imposes a revision of the rat amylin role [85].

The effect of $\mathrm{Zn}$ (II) on hIAPP fibrillogenesis and toxicity is of particular interest as $\beta$-cell granules contain millimolar concentrations of $\mathrm{Zn}$ (II), one of the highest levels in the body, and diabetics often exhibit zinc deficiency $[5,86,87]$. $\mathrm{Zn}$ (II) has a strong effect on hIAPP aggregation, although different from that one observed for $\mathrm{A} \beta$; however, the physical basis of the effect is complex [88]. $\mathrm{Zn}$ (II) has generally an inhibitory effect on hIAPP aggregation since H18 is the only residue that changes the protonation state between $\mathrm{pH} 7.5$ and $\mathrm{pH}$ 5.5. The $\mathrm{pH}$ dependence can be attributed to the protonation of H18, suggesting that the binding is localized near H18. NMR confirms this hypothesis by revealing that the greatest chemical shift perturbation accompanying binding of $\mathrm{Zn}(\mathrm{II})$ is localized near $\mathrm{H} 18$ [5, 68]. Since binding of $\mathrm{Zn}$ (II) to human amylin near $\mathrm{H} 18$ would result in electrostatic repulsion between adjacent $\beta$-sheets, this would disfavour the formation of mature fibrils $[5,89]$.

Another study shows that zinc binds and stabilizes prefibrillar aggregates of amylin during the lag-phase [60]. Zinc 
is involved in many aspects of glucose homeostasis, including paracrine regulation, insulin storage, and glucose stimulated cascades [90]. In $\beta$-cells zinc was proposed to be required for multiple steps in insulin synthesis crystallization and release $[91,92]$, but conclusive evidence is lacking. Interestingly mice lacking the only zinc transporter in $\beta$-cells, the ZnT8, were shown to become glucose intolerant when fed with a high fat diet [93].

\section{Proposed Mechanisms and Pathways Involved in IAPP Cytotoxicity}

Current studies performed in primates strongly support the concept that islet amyloidosis and $\beta$-cell apoptosis are two key determinants of islet dysfunction in T2DM [94-96]. The notion that IAPP evokes degeneration of pancreatic $\beta$-cells is nowadays acknowledged, but neither the precise nature of the harmful IAPP species nor the mechanisms of cytotoxicity have been clarified. Most studies carried out during the last decade have pointed out that hIAPP amyloid fibrils do not contribute directly to IAPP cytotoxicity, since there is no strong correlation between the extent of amyloid deposits and the disease severity [97]. A growing body of evidence has instead supported the toxic oligomer hypothesis which proposes that small membrane-permeant human amylin oligomers are the toxic form responsible for $\beta$-cell death. Konarkowska and colleagues found that mature hIAPP fibrils were not cytotoxic in vitro; rather the transition from random coil to $\beta$-sheet, coupled with de novo aggregation, was necessary for the induction of $\beta$-cells death [98]. In line with this concept, it was shown that rifampicin [99] which is able to prevent hIAPP fibrillization but not hIAPP oligomer formation [100] did not protect $\beta$-cells from apoptosis induced by either overexpression or application of hIAPP [101]. Similar amyloid aggregation and toxicity behaviours were also observed for other amyloidogenic peptides including amyloid- $\beta$ linked to Alzheimer's disease and $\alpha$-synuclein linked to Parkinson's disease $[102,103]$. hIAPP toxic oligomers are present in $\beta$-cells of patients with T2DM and increase in abundance with obesity. Recently, antibodies which specifically recognized these assemblies, but not monomers or amyloid fibrils, have been exclusively identified in diabetic patients and have been shown to neutralize the apoptotic effect induced by these oligomers [104]. The presence of antibodies in sera of diabetic patients provides very strong evidence in support of the pathological relevance of the oligomers [105].

Another big unsolved issue is whether the hIAPP-induced apoptosis is triggered by species formed outside or inside cells. Based on studies carried out using cultured $\beta$-cells or transgenic animal model susceptible to hIAPP-evoked diabetes, $\beta$-cell apoptosis may be activated by hIAPP oligomers originating either on the surface of cells or within them $[95,97,106-110]$. IAPP oligomers in diabetic patients have been detected throughout the secretory pathway and are often associated with disrupted mitochondrial membranes [111] implying intracellular formation. Also oligomer immunoreactivity has been demonstrated by light microscopy in islets from hIAPP transgenic mice, but not in mice overexpressing comparable levels of nonamyloidogenic rodent IAPP or wild-type mice. Immunization against toxic oligomers did not protect these mice from developing diabetes, indirectly suggesting that toxic IAPP oligomers originate and act intracellularly $[112,113]$. Recently, by using confocal microscopy, independent groups revealed that exogenous IAPP can enter the cell and this is associated with signs of cell death [32, 33]. Several mechanisms of toxicity, including receptor and nonreceptor-mediated events, have been proposed. A consensus in the field has been growing about the role of hIAPP interactions with cell membranes enabling disruption the cell membranes integrity, permeability, and functions, resulting in ions dishomeostasis, changes in signalling pathways, oxidative injury, and ultimately apoptotic cell death (for a detailed review see [114]).

3.1. IAPP-Induced Structural Alteration of Extra- and Intracellular Membranes. IAPP is natively unstructured but gains $\alpha$-helical structure upon binding to anionic membranes and forms $\beta$-sheet-rich amyloid fibers during the progression of type II diabetes. Interaction between IAPP and cellular membranes was proposed as the cause of IAPP cytotoxicity and $\beta$-cell death in T2DM, since detailed ultrastructural investigations have revealed that islet amyloid was often in contact with $\beta$-cell membranes [115] and because these membranes presented concomitant morphological changes [116]. An important amount of data exists suggesting that toxic oligomers may be formed within membranes [42, 117-119]. Furthermore, the observation that toxic IAPP oligomers may escape from the secretory pathway, presumably by disrupting membranes of ER, Golgi, and secretory vesicles, is consistent with in vitro studies noting that toxic oligomers of amyloidogenic proteins induce membrane permeability and membrane disruption $[42,118-120]$. It should be noted that since the combination of hIAPP and membranes in nondiabeticpeople does not normally result in $\beta$-cell death, particular T2DM-related surrounding conditions should exist that initiate hIAPP-induced membrane damage. An increase in the level of hIAPP, which is coproduced and cosecreted with insulin, in a state of insulin resistance, could initiate hIAPP oligomerization. More specifically, an altered ratio of insulin to hIAPP, as observed in diabetic patients [121], could lead to a decrease of the inhibitory effect of insulin on hIAPP amyloid fibril formation. However, the inhibition of insulin on hIAPP aggregation is only based on in vitro studies $[122,123]$. On the other hand, a modified lipid composition of the $\beta$-cells, in particular an increase in negatively charged lipids, as inferred from studies with mouse and rat models for T2DM [124] could trigger an increase in hIAPP-membrane interactions. In vitro studies have shown that negatively charged lipids increase the rate of hIAPP fibril formation $[125,126]$ and also enhance hIAPP-induced membrane damage $[127,128]$. The membrane itself could promote hIAPP growth by increasing the local concentration of (membrane bound) hIAPP and/or by promoting a specific orientation or conformation of the peptide that makes hIAPP molecules more susceptible to aggregation into oligomers or fibrils. Recent research shows that not only phospholipid bilayers, but also a polyanion like heparin [129] or a dichloromethane/water 
interface [130], can induce nucleation and aggregation of hIAPP. Finally glycosaminoglycans chains of the heparin sulfate proteoglycan (HSPG) Perlecan have been shown to significantly accelerate amyloid formation from IAPP and from the partially processed forms of pro-IAPP in vitro [131]. These results indicate that the overall charge of membrane, a hydrophobic/hydrophilic interface (both present in biological membranes), and some surrounding molecules are important factors that promote hIAPP fibril formation. In the case of the Alzheimer's disease-related A $\beta$ peptide, it has been suggested that not a particular species but the ongoing amyloid fibrillogenesis is the true cause that is responsible for membrane damage [132]. Altogether, these notions suggest that a cytotoxic mechanism based on fibril growth at the membrane could represent a common mechanism for amyloid-induced cell death. Interactions of membrane-located hIAPP species with each other, or with hIAPP species in solution, lead to growth of fibrils at the membrane. The mechanism of membrane damage could entail growth of a rigid hIAPP fibril on a flexible phospholipids bilayer, which would result in a forced change in membrane curvature, deformation disruption, blebbing, and vesicle budding of cell membranes as observed in the presence of synthetic and cell-derived hIAPP $[33,116,118]$.

A number of factors related to the formation of membrane-permeant oligomers might contribute to the dysfunction of pancreatic $\beta$-cells in T2DM in analogous of neurons in neurodegenerative diseases. Some of them will be discussed more in depth in the following sections.

\subsection{IAPP-Induced Calcium Dyshomeostasis, ER Stress, and} Autophagy. The delivery of toxic oligomers to the extra- or intracellular membranes might be expected to significantly affect signalling pathways involved in cell survival and cell death.

Calcium homeostasis and signalling not only is important for cell survival but also underpins the intracellular trafficking and regulated discharge of secretory and synaptic vesicles at the cell membrane. Remarkably, an increase in the intracellular $\mathrm{Ca}^{2+}$ concentration has been described as being provoked by amyloid oligomers in neurons and astrocytes $[133,134]$. Notably $\mathrm{Ca}^{2+}$ concentration has been suggested to be an important cofactor able to modulate the mechanism of membrane destabilization, favouring one mechanism rather than another. In particular the presence of $\mathrm{Ca}^{2+}$ seems to enhance membrane disruption induced by hIAPP fibers through detergent like mechanism [135]. Yet, unregulated remodelling of the tubulin cytoskeleton consequent on hyperactivation of $\mathrm{Ca}^{2+}$ sensitive calpain might contribute to impaired intracellular vesicle trafficking [136], resulting in altered secretion of insulin and/or IAPP, exacerbating T2DM degenerations.

Several studies have reported that hIAPP overexpression or exposure induces defects in glucose stimulated insulin secretion (GSIS), possibly due to its capacity to aggregate and form intracellular oligomers [137, 138]. Zhu et al. [139] demonstrated that high concentrations of hIAPP inhibited the activity of voltage-gated calcium channels VCC, leading to a defect in the intracellular $\mathrm{Ca}^{2+}$ mobilization in pancreatic islets. They also suggested that this could explain the failure in GSIS. Soty and coworker overexpressed hIAPP in rat pancreatic islets using lentiviral infection, which allows long term hIAPP overexpression, and demonstrated that hIAPP overexpression altered the activity of the ATP-sensitive potassium channels (KATP), leading to defects in insulin and IAPP secretion in response to glucose. Moreover, authors reported an associated increase in ROS production and mitochondrial activity interpreted as a compensatory mechanism for counteracting these defects. Elevated ROS levels can, in turn, lead to the progressive loss of $\beta$-cell function therefore contributing to the further worsening of the T2DM pathological condition [140]. Other mechanisms described to account for IAPP-induced GSIS include the direct formation of $\mathrm{Ca}^{2+}$ permeable pores by the amyloid oligomers themselves and/or the activation of VCC [141] not only in the plasma membrane but also in the ER. ER stress has been proposed as being an important contributor to hIAPP-induced $\beta$-cell death since oligomeric hIAPP has been detected in ER membranes and exogenously added hIAPP has been reported to induce ER stress $[111,142]$. However, the role of ER stress in hIAPP mediated toxicity in vivo is controversial, since ER stress is important in transgenic models that overexpress hIAPP at high levels but is not detected when lower levels of IAPP are produced in cultured islet [140-143]. Indeed, theoretically the ER is well defended from misfolding by the unfolded protein response, high concentrations of chaperon proteins, high $\mathrm{Ca}^{2+}$ concentration, and an oxidative environment. Mature insulin secretory vesicles should also be relatively protected from hIAPP aggregation because of the acidic $\mathrm{pH}$ and the high insulin concentration, both factors being known for their ability to inhibit IAPP aggregation [144, 145]. It should also be taken in consideration that in long-lived secretory cells, such as pancreatic $\beta$-cells, bearing a high burden of protein synthesis and folding, the disposal of misfolded or denatured proteins, and particularly those with a potential to form toxic oligomers, is essential. Therefore the detected increased toxic IAPP oligomers in T2DM may be due to defective oligomer removal [146]. The autophagy/lysosome system plays a key role in cellular adaptation to stress via clearance of misfolded proteins, damaged organelles, and/or oligomerizationprone proteins $[147,148]$ It has been reported that while proteasomal degradation is a critical part of the clearance of nonaggregate-prone proteins, intracellular accumulation of abnormal aggregated proteins in neurodegenerative diseases, such as amyloid plaque formation in Alzheimer's disease $(\mathrm{AD})$, is associated with malfunction of autophagy [149]. Hence, autophagy seems to be more important for the removal of amyloidogenic hIAPP and disregulated autophagy may be more relevant to the pathogenesis of human T2DM rather than that of murine T2DM. In 2014 three independent groups have demonstrated that exposure of cultured $\beta$-cells to hIAPP increases autophagosome formation and that the inhibition of autophagy increases the vulnerability of $\beta$-cells to the cytotoxic effects of hIAPP. In mice with $\beta$-cells-specific expression of hIAPP, a deficiency in autophagy resulted in the development of overt diabetes, which was not observed in 
mice expressing hIAPP alone or lacking autophagy alone. Furthermore, lack of autophagy in hIAPP-expressing animals resulted in hIAPP oligomerization and amyloid accumulation in pancreatic islets, leading to increased $\beta$-cells death [150]. Also treatment of INS-1 cells with hIAPP enhanced cell death, inhibited cytoproliferation, and increased autophagosome formation [151].

\subsection{IAPP-Induced Oxidative Stress and Mitochondrial Impair-} ment. Oxidative stress, which is an imbalance between the generation of ROS and the cells antioxidant defence capacities provided by glutathione and other reducing molecules, has been associated with a number of diseases, including cancer, heart diseases, Alzheimer's disease (AD), and T2DM [152]. At high concentrations, ROS can cause significant damage to cell structures, nucleic acids, lipids, and proteins, leading to apoptotic or necrotic cell death. Growing support for the involvement of oxidative stress in islet dysfunction and death has also been discussed [153]. Interestingly, antioxidant treatments have been shown to be effective in reducing ROS levels and $\beta$-cells apoptosis, suggesting that ROS mediate in IAPP toxicity $[33,108,154,155]$. Being the energetic core of the cell, mitochondria represents also the main source of oxygen radicals, and alteration in the bioenergetic equilibrium of cells often results in oxidative stress. Therefore, it is not surprising that both alteration in mitochondrial impairment and oxidative stress are associated to a given disorder. The disruption of mitochondrial membranes by proximate toxic oligomers, which escaped from the secretory pathway, also provides a mechanism for the well-recognized contribution of mitochondrial dysfunction to overall cellular dysfunction in both $\beta$-cells in T2DM and neurons in neurodegenerative diseases $[106,156-158]$. By using quantitative proteomics, Lim and coworker [159] demonstrated that hIAPP gains toxic features affecting the oxidative phosphorylation (OXPHOS) system, which includes the electron transport system (complexes I to IV) and $\mathrm{F}_{1} \mathrm{~F}_{0}$ ATP synthase (complex V), the oxygen consumption (as measured by an altered respiratory states), and the ROS levels. This demonstrates that different regulatory systems of the cells, associated with mitochondrial function and metabolism, are deregulated by hIAPP emphasising a role for oxidative stress in T2DM. Accordingly, cryoimmunogold labelling has also been used to directly reveal that the toxic oligomers of IAPP form within the secretory pathway, escaping and disrupting cellular membranes including mitochondrial membranes $[112,113]$. A recent hypothesis was made in order to explain the ability of IAPP to enter the cell. The clustering of positive charges from each IAPP peptide chain at the interface with membrane would result in the formation of membrane-bound $\alpha$-helical aggregates endowed with cell penetrating features [32]. It has been recently reported that also hIAPP17-29 enters the cell despite possessing only the histidine residue as possible cationising site. As expected for cationic molecules, both fluorescent F-hIAPP17-29 and F-hIAPP1-37 can be taken up into the mitochondrial matrix. The presence of this cationic peptide in the matrix leads to mitochondrial depolarization, opening of the permeability transition pore (PTP), causing swelling and rupture of the outer mitochondrial membrane, thus resulting in the rapid release of the peptide in the cytoplasm. In fact, mitochondrial swelling leads to the leakage of a series of mitochondrial proapoptotic factors resulting in cell death [160]. Therefore these mitochondrial toxic peptides selectively target the respiratory complexes I and II causing oxidative phosphorylation deficits and consequently the impairment of ATP production, oxidative stress, and energy deficits, ultimately resulting in cell death induction [161]. Disruption of the lysosomal compartment may also affect the redox balances of the cell.

\subsection{Involvement of Death Receptors and Kinases Signalling} in IAPP-Induced Apoptosis. Several groups have described activation of multiple apoptosis pathways following hIAPP exposure, including the sequential activation of caspase8 and caspase- 3 and the Jun $\mathrm{NH}_{2}$-terminal kinase (JNK)1/c-Jun and p38 kinase pathways [162]. Oligomeric hIAPP might interact with $\beta$-cell membranes in a specific manner that activates death receptor signaling to trigger apoptosis. Several death receptor-signalling/death receptor-inducing molecules, including Fas and Fas-associated death domain (FADD), have been implicated in $\beta$-cell destruction in various cellular and animal models of immune-mediated diabetes and type 1 diabetic individual. Increased $\beta$-cell Fas expression has also been reported in type 2 diabetic individuals [163]. Cell-surface death receptor Fas and the related death domain protein FADD were shown to be important contributors in the pathway by which hIAPP evokes $\beta$-cell apoptosis [164].

Numerous studies have also indicated that the c-Jun Nterminal kinase (JNK) pathway has also been reported as a critical mediator of $\beta$-cell apoptosis induced by both exogenous and endogenous hIAPP. Islet amyloid increased mRNA levels of both the extrinsic (Fas, Fadd) and the intrinsic (Bim) apoptotic pathways markers, caspase-3, and the antiapoptotic molecule Bclxl in a JNK-dependent manner [155].

\section{The Nonfibrillogenic Rat IAPP Can Turn Toxic to $\beta$-Cells}

Unlike hIAPP, rat IAPP (rIAPP) is a nonamyloidogenic form that does not accumulate and does not induce oligomer and/ or fibril deposition in $\beta$-cells [23-28]. However, a conspicuous body of evidence is emerging suggesting that nonfibrillogenic rodent IAPP species may also be harmful to $\beta$-cells. For instance, rIAPP was found that to produce comparable $\mathrm{H}_{2} \mathrm{O}_{2}$ concentrations, indicating that amylin aggregation and amylin-induced ROS are unrelated processes [83]. Remarkably, some authors demonstrated that the full-length rIAPP peptide and its short derivate rIAPP17-29 are cytotoxic to cultured RIN-M cells and this effect is reverted by previous treatment with antioxidants [33]. Similar experimental evidence about the rIAPP1-37 cytotoxicity was also reported by others [32, 165]. Yet, considering some recent papers dealing with $\mathrm{rIAPP} / \mathrm{membrane}$ interaction $[34,166]$ together with the evidence that small aggregates can be detected also in rIAPP samples, an rIAPP-associated cytotoxicity could be conceivable. Very recent work attempted establishing the relationship between the observed cytotoxicity of rIAPP1-37 and rIAPP8-37 and their ability to form aggregated species. 
Authors observed that, in analogy to hIAPP, rIAPP toxicity could be inhibited by an amylin receptor antagonist (AC 187) and a caspase inhibitor (zVAD-fmk). In addition they did not rule out any possible contribution of rIAPP oligomeric species to the toxicity of their preparations [165]. Conversely, in keeping with the in vitro evidence that no aggregated forms could be detected for rIAPP by using CD and DLS experiments, $\beta$-cells treated with rIAPP1 were not reactive when immunostained with the All antibody, suggesting that oligomers formation is not a stringent prerequisite for the observed rIAPP cytotoxicity. At the moment the hypothesis which seems more appropriate is that rIAPP toxicity might relate to a different mechanism compared to hIAPP. As a matter of fact fluorescent rat IAPP was detected in the lysosomal/ endosomal compartment, whereas fluorescent hIAPP was seen in mitochondria [33]. As Magzoub and Miranker hypothesized, rat IAPP can be endocytosed and accumulated into lysosomes where it reaches a critical concentration, resulting in organelle membrane disruption and cytotoxicity [32]. In line with this hypothesis, it was observed that prolonged incubation of the fluorescent rIAPP resulted in spreading of the fluorescent signal throughout the cytosol, thereby suggesting that the peptide has disrupted the lysosomal membrane. This event was associated with the condensation of nuclei and the appearance of other morphological alterations typical of apoptosis [33].

\section{Molecular Links between T2DM and AD}

A variety of interconnecting factors links T2DM with Alzheimer's disease AD [167-169]. This would be not surprising given that aging is a well-known common risk factor for both pathologies. From a conformational point of view hIAPP and $\mathrm{A} \beta$ are more than unrelated molecules: both can populate several conformational states ranging from random coil to $\alpha$-helix or $\beta$-sheet structures depending on the environmental surroundings. Similar to A $\beta$, IAPP is mainly unstructured in the monomeric state, but it can readily adopt $\alpha$-helical conformation in the presence of helix-inducing fluorinated alcohols (TFE and HFIP) [170] or both $\alpha$-helical and $\beta$-sheet conformations in a membrane mimicking environment $[171,172]$. Amyloid cytotoxicity by membrane damage has been suggested not only for hIAPP but also for $\mathrm{A} \beta$, and induction of nonselective ion channels and/or disruption of membranes of the secretory pathway is also consistent with cytotoxicity mediated by increased cytosolic $\mathrm{Ca}^{2+}$ in $\mathrm{AD}[136$, $173,174]$. Oligomerization/aggregation of $A \beta$ and hIAPP that induce oxidative stress in neurons and $\beta$-cells, respectively, as well as elevated tissue copper levels found in the brain and pancreas of the subjects harbouring amyloid plaques, are also common features shared by T2DM and AD pathologies. Despite the absence of a large sequence homology between A $\beta$ and hIAPP (about 25\% sequence identity and 50\% sequence similarity) both aggregated oligomeric forms of these peptides display a common conformation structure [175]. In both cases, the oligomer toxicity is inhibited by oligomeric-specific antibodies, which suggests a common mechanism of toxicity shared by the two fibrillogenic peptides [176]. Finally both A $\beta$ and hIAPP are substrates for insulin degrading enzyme (IDE) a metalloprotease involved in the homeostasis of these two peptides in the brain [177179].

Disturbance of $\mathrm{Cu}(\mathrm{II})$ and $\mathrm{Zn}(\mathrm{II})$ physiological levels is another factor joining T2DM and AD. Whereas $\mathrm{A} \beta$-metal ion interaction has been extensively investigated, since the recognition of the fundamental role played by transition metal ions dyshomeostasis in the etiopathology of AD [180-184], less data is available from the literature concerning the role played by $\mathrm{Cu}$ (II) or $\mathrm{Zn}$ (II) in the IAPP-associated aggregation and toxicity in T2DM. In $\mathrm{A} \beta$, metal ion interactions occur mainly within the 1-16 N-terminal region where a variety of metal coordinating functional groups, from the side chains of the His, Asp, or Glu aminoacid residues, in addition to the Nterminal free amino group, are present. By contrast in hIAPP the imidazole moiety of the histidyl residue at position 18 and the N-terminal amino group are the only physiologically relevant anchoring sites for metal coordination. A lower affinity for these metal ions is therefore expected for hIAPP in comparison with $\mathrm{A} \beta$.

The similar pathological parallels between AD and T2DM have allowed recent hypotheses suggesting that $\mathrm{AD}$ might be considered as a neuroendocrine-like disorder, in other words a sort of "type 3 diabetes" [185]. Epidemiological studies indicate that the incidence of AD is 2 to 5 times higher in individuals with T2DM [186]. Insulin resistance and metabolic dysfunction related with impaired glycemia in T2DM have been related to cognitive decline in MCI cases [187]. Both $\mathrm{T} 2 \mathrm{DM}$ and $\mathrm{AD}$ are characterized by insoluble $\beta$-sheet rich fibrillar aggregates of IAPP or $\mathrm{A} \beta$ peptides in the pancreas and brain, respectively. IAPP aggregation is associated with pancreatic $\beta$-cell loss, whereas clumps of $A \beta$ lead to neuronal cell loss. The recent identification of deposits of amylin in the brains of people with Alzheimer's disease, as well as combined deposits of amylin and $\mathrm{A} \beta$ plaques, strengthens evidence on the relationship between T2DM and AD indicating also that amylin is a second amyloid and, potentially, a new biomarker for age-related dementia and Alzheimer's [188]. Finally, it is noteworthy that the monomeric form of $\mathrm{A} \beta$ seems to behave as a brain protective factor able to regulate synaptic activity and to activate insulin/IGF-1 receptor signalling. Thus it has been suggested that depletion of $\beta$-amyloid monomers, occurring in the preclinical phase of $\mathrm{AD}$, might be the cause of early insulin/IGF-1 signalling disturbances that anticipate cognitive decline $[189,190]$.

\section{Conclusions}

According to major research, amylin or IAPP is a pancreatic peptide hormone naturally produced with insulin and appears to be involved in the cause of both main types of diabetes. Current efforts are focused on understanding the local environmental conditions and interactions with metal ion that can directly influence IAPP aggregation process. The molecular mechanisms underlying amyloid formation are not completely known and particularly their temporal sequence, the hierarchy, and the threshold dividing physiology from pathology are unknown. 
That T2DM causes severe brain injury with time is already known, and although there has been a lot of speculation about why that occurs, no conclusive evidence has been found until now. Amylin can readily cross the blood brain barrier (BBB) and presumably interact with $A \beta$ in the brain. There is clear evidence that amylin may be associated with $\mathrm{A} \beta$, but the nature of their relationship remains unclear. In any case, the consciousness of such a high connection may support the idea that beneficial therapeutic strategies against T2DM might also be beneficial against AD. Thus research efforts at preventing oligomers and fibril formation by IAPP, together with a clear elucidation of the role played by metal ions in T2DM, might represent a new research field attempting to develop drugs as a cure for both pathologies [191-195].

\section{Conflict of Interests}

The authors declared no conflict of interests.

\section{Acknowledgment}

The authors wish to thank FIRB-Merit RBNE08HWLZ for financial support.

\section{References}

[1] M. Kitada, Z. Zhang, A. Mima, and G. L. King, "Molecular mechanisms of diabetic vascular complications," Journal of Diabetes Investigation, vol. 1, no. 3, pp. 77-89, 2010.

[2] S. Wild, G. Roglic, A. Green, R. Sicree, and H. King, "Global prevalence of diabetes: estimates for the year 2000 and projections for 2030," Diabetes Care, vol. 27, no. 5, pp. 1047-1053, 2004.

[3] A. Clark, E. J. P. De Koning, A. T. Hattersley, B. C. Hansen, C. S. Yajnik, and J. Poulton, "Pancreatic pathology in non-insulin dependent diabetes (NIDDM)," Diabetes Research and Clinical Practice, vol. 28, pp. S39-S47, 1995.

[4] J. W. M. Höppener, B. Ahrén, and C. J. M. Lips, "Islet amyloid and type 2 diabetes mellitus," The New England Journal of Medicine, vol. 343, no. 6, pp. 411-419, 2000.

[5] A. S. Detoma, S. Salamekh, A. Ramamoorthy, and M. H. Lim, "Misfolded proteins in Alzheimer's disease and type II diabetes," Chemical Society Reviews, vol. 41, no. 2, pp. 608-621, 2012.

[6] K. H. Johnson, T. D. O’Brien, and P. Westermark, "Newly identified pancreatic protein islet amyloid polypeptide: what is its relationship to diabetes?" Diabetes, vol. 40, no. 3, pp. 310-314, 1991.

[7] T. Sanke, G. I. Bell, C. Sample, A. H. Rubenstein, and D. F. Steiner, "An islet amyloid peptide is derived from an 89-amino acid precursor by proteolytic processing," Journal of Biological Chemistry, vol. 263, no. 33, pp. 17243-17246, 1988.

[8] L. Marzban, G. Trigo-Gonzalez, and C. B. Verchere, "Processing of pro-islet amyloid polypeptide in the constitutive and regulated secretory pathways of $\beta$ cells," Molecular Endocrinology, vol. 19, no. 8, pp. 2154-2163, 2005.

[9] S. E. Kahn, D. A. D’Alessio, M. W. Schwartz et al., "Evidence of cosecretion of islet amyloid polypeptide and insulin bv $\beta$-cells," Diabetes, vol. 39, no. 5, pp. 634-638, 1990.

[10] L. M. McLatchie, N. J. Fraser, M. J. Main et al., "RAMPS regulate the transport and ligand specificity of the calcitonin-receptorlike receptor," Nature, vol. 393, no. 6683, pp. 333-339, 1998.
[11] R. Muff, N. Bühlmann, J. A. Fischer, and W. Born, "An amylin receptor is revealed following co-transfection of a calcitonin receptor with receptor activity modifying proteins-1 or -3 ," Endocrinology, vol. 140, no. 6, pp. 2924-2927, 1999.

[12] D. R. Poyner, P. M. Sexton, I. Marshall et al., "International Union of Pharmacology. XXXII: the mammalian calcitonin gene-related peptides, adrenomedullin, amylin, and calcitonin receptors," Pharmacological Reviews, vol. 54, no. 2, pp. 233-246, 2002.

[13] T. A. Lutz, "The role of amylin in the control of energy homeostasis," The American Journal of Physiology-Regulatory Integrative and Comparative Physiology, vol. 298, no. 6, pp. R1475R1484, 2010.

[14] P. Westermark, A. Andersson, and G. T. Westermark, "Islet amyloid polypeptide, islet amyloid, and diabetes mellitus," Physiological Reviews, vol. 91, no. 3, pp. 795-826, 2011.

[15] J. Montane, A. Klimek-Abercrombie, K. J. Potter, C. WestwellRoper, and C. B. Verchere, "Metabolic stress, IAPP and islet amyloid," Diabetes, Obesity and Metabolism, vol. 14, no. 3, pp. 68-77, 2012.

[16] Z.-L. Wang, W. M. Bennet, M. A. Ghatei, P. G. H. Byfield, D. M. Smith, and S. R. Bloom, "Influence of islet amyloid polypeptide and the 8-37 fragment of islet amyloid polypeptide on insulin release from perifused rat islets," Diabetes, vol. 42, no. 2, pp. 330335, 1993.

[17] A. Young, "Inhibition of insulin secretion," Advances in Pharmacology, vol. 52, pp. 173-192, 2005.

[18] T. Riediger, M. Rauch, and H. A. Schmid, "Actions of amylin on subfornical organ neurons and on drinking behavior in rats," American Journal of Physiology: Regulatory Integrative and Comparative Physiology, vol. 276, no. 2, pp. R514-R521, 1999.

[19] R. D. Reidelberger, A. C. Haver, U. Arnelo, D. D. Smith, C. S. Schaffert, and J. Permert, "Amylin receptor blockade stimulates food intake in rats," American Journal of Physiology: Regulatory Integrative and Comparative Physiology, vol. 287, no. 3, pp. R568-R574, 2004.

[20] C. S. Potes and T. A. Lutz, "Brainstem mechanisms of amylininduced anorexia," Physiology and Behavior, vol. 100, no. 5, pp. 511-518, 2010.

[21] J. L. Trevaskis, D. G. Parkes, and J. D. Roth, "Insights into amylin-leptin synergy," Trends in Endocrinology and Metabolism, vol. 21, no. 8, pp. 473-479, 2010.

[22] A. Abedini and A. M. Schmidt, "Mechanisms of islet amyloidosis toxicity in type 2 diabetes," FEBS Letters, vol. 587, no. 8, pp. 1119-1127, 2013.

[23] P. Westermark, U. Engstrom, K. H. Johnson, G. T. Westermark, and C. Betsholtz, "Islet amyloid polypeptide: pinpointing amino acid residues linked to amyloid fibril formation," Proceedings of the National Academy of Sciences of the United States of America, vol. 87, no. 13, pp. 5036-5040, 1990.

[24] C. Betsholtz, L. Christmansson, U. Engstrom et al., "Sequence divergence in a specific region of islet amyloid polypeptide (IAPP) explains differences in islet amyloid formation between species," FEBS Letters, vol. 251, no. 1-2, pp. 261-264, 1989.

[25] S. J. Wimalawansa, "Amylin, calcitonin gene-related peptide, calcitonin, and adrenomedullin: a peptide superfamily," Critical Reviews in Neurobiology, vol. 11, no. 2-3, pp. 167-239, 1997.

[26] A. Abedini, F. Meng, and D. P. Raleigh, "A single-point mutation converts the highly amyloidogenic human islet amyloid polypeptide into a potent fibrillization inhibitor," Journal of the American Chemical Society, vol. 129, no. 37, pp. 11300-11301, 2007. 
[27] F. Meng, D. P. Raleigh, and A. Abedini, "Combination of kinetically selected inhibitors in Trans leads to highly effective inhibition of amyloid formation," Journal of the American Chemical Society, vol. 132, no. 41, pp. 14340-14342, 2010.

[28] L.-M. Yan, M. Tatarek-Nossol, A. Velkova, A. Kazantzis, and A. Kapurniotu, "Design of a mimic of nonamyloidogenic and bioactive human islet amyloid polypeptide (IAPP) as nanomolar affinity inhibitor of IAPP cytotoxic fibrillogenesis," Proceedings of the National Academy of Sciences of the United States of America, vol. 103, no. 7, pp. 2046-2051, 2006.

[29] A. Abedini and D. P. Raleigh, "Destabilization of human IAPP amyloid fibrils by proline mutations outside of the putative amyloidogenic domain: is there a critical amyloidogenic domain in human IAPP?" Journal of Molecular Biology, vol. 355, no. 2, pp. 274-281, 2006.

[30] B. W. Koo, J. A. Hebda, and A. D. Miranker, "Amide inequivalence in the fibrillar assembly of islet amyloid polypeptide," Protein Engineering, Design and Selection, vol. 21, no. 3, pp. 147154, 2008

[31] A. Fox, T. Snollaerts, C. Errecart Casanova, A. Calciano, L. A. Nogaj, and D. A. Moffet, "Selection for nonamyloidogenic mutants of islet Amyloid Polypeptide (IAPP) identifies an extended region for amyloidogenicity," Biochemistry, vol. 49, no. 36, pp. 7783-7789, 2010.

[32] M. Magzoub and A. D. Miranker, "Concentration-dependent transitions govern the subcellular localization of islet amyloid polypeptide," FASEB Journal, vol. 26, no. 3, pp. 1228-1238, 2012.

[33] M. F. Tomasello, A. Sinopoli, F. Attanasio et al., "Molecular and cytotoxic properties of hIAPP17-29 and rIAPP17-29 fragments: a comparative study with the respective full-length parent polypeptides," European Journal of Medicinal Chemistry, vol. 81, pp. 442-455, 2014.

[34] J. R. Brender, S. Salamekh, and A. Ramamoorthy, "Membrane disruption and early events in the aggregation of the diabetes related peptide IAPP from a molecular perspective," Accounts of Chemical Research, vol. 45, no. 3, pp. 454-462, 2012.

[35] N. A. Bernhardt, W. M. Berhanu, and U. H. E. Hansmann, "Mutations and seeding of amylin fibril-like oligomers," Journal of Physical Chemistry B, vol. 117, no. 50, pp. 16076-16085, 2013.

[36] A. Clark, D. R. Matthews, B. A. Naylor, C. A. Wells, J. P. Hosker, and R. C. Turner, "Pancreatic islet amyloid and elevated proinsulin secretion in familial maturity-onset diabetes," Diabetes Research, vol. 4, no. 2, pp. 51-55, 1987.

[37] S. Luca, W.-M. Yau, R. Leapman, and R. Tycko, "Peptide conformation and supramolecular organization in amylin fibrils: constraints from solid-state NMR," Biochemistry, vol. 46, no. 47, pp. 13505-13522, 2007.

[38] A. V. Kajava, U. Aebi, and A. C. Steven, "The parallel superpleated beta-structure as a model for amyloid fibrils of human amylin," Journal of Molecular Biology, vol. 348, no. 2, pp. 247252, 2005.

[39] M. F. M. Engel, "Membrane permeabilization by Islet Amyloid Polypeptide," Chemistry and Physics of Lipids, vol. 160, no. 1, pp. 1-10, 2009.

[40] K. Sasahara, K. Morigaki, and K. Shinya, "Amyloid aggregation and deposition of human islet amyloid polypeptide at membrane interfaces," FEBS Journal, vol. 281, no. 11, pp. 2597-2612, 2014.

[41] N. B. Last and A. D. Miranker, "Common mechanism unites membrane poration by amyloid and antimicrobial peptides," Proceedings of the National Academy of Sciences of the United States of America, vol. 110, no. 16, pp. 6382-6387, 2013.
[42] T. A. Mirzabekov, M.-C. Lin, and B. L. Kagan, "Pore formation by the cytotoxic islet amyloid peptide amylin," Journal of Biological Chemistry, vol. 271, no. 4, pp. 1988-1992, 1996.

[43] P. Cao, P. Marek, H. Noor et al., "Islet amyloid: from fundamental biophysics to mechanisms of cytotoxicity," FEBS Letters, vol. 587, no. 8, pp. 1106-1118, 2013.

[44] M. Wakabayashi and K. Matsuzaki, "Ganglioside-induced amyloid formation by human islet amyloid polypeptide in lipid rafts," FEBS Letters, vol. 583, no. 17, pp. 2854-2858, 2009.

[45] S. Trikha and A. M. Jeremic, "Clustering and internalization of toxic amylin oligomers in pancreatic cells require plasma membrane cholesterol," The Journal of Biological Chemistry, vol. 286, no. 41, pp. 36086-36097, 2011.

[46] J. Seeliger, K. Weise, N. Opitz, and R. Winter, “The effect of A $\beta$ on IAPP aggregation in the presence of an isolated $\beta$-cell membrane," Journal of Molecular Biology, vol. 421, no. 2-3, pp. 348363, 2012.

[47] J. D. Knight, J. A. Williamson, and A. D. Miranker, "Interaction of membrane-bound islet amyloid polypeptide with soluble and crystalline insulin," Protein Science, vol. 17, no. 10, pp. 1850-1856, 2008.

[48] W.-J. Cho, S. Trikha, and A. M. Jeremic, "Cholesterol regulates assembly of human islet amyloid polypeptide on model membranes," Journal of Molecular Biology, vol. 393, no. 3, pp. 765775, 2009.

[49] K. Weise, D. Radovan, A. Gohlke, N. Opitz, and R. Winter, "Interaction of hIAPP with model raft membranes and pancreatic $\beta$-cells: cytotoxicity of hIAPP oligomers," ChemBioChem, vol. 11, no. 9, pp. 1280-1290, 2010.

[50] G. P. Gellermann, T. R. Appel, A. Tannert et al., "Raft lipids as common components of human extracellular amyloid fibrils," Proceedings of the National Academy of Sciences of the United States of America, vol. 102, no. 18, pp. 6297-6302, 2005.

[51] M. F. M. Engel, H. Yigittop, R. C. Elgersma et al., "Islet amyloid polypeptide inserts into phospholipid monolayers as monomer," Journal of Molecular Biology, vol. 356, no. 3, pp. 783-789, 2006.

[52] R. P. R. Nanga, J. R. Brender, J. Xu, G. Veglia, and A. Ramamoorthy, "Structures of rat and human islet amyloid polypeptide IAPP1-19 in micelles by NMR spectroscopy," Biochemistry, vol. 47, no. 48, pp. 12689-12697, 2008.

[53] R. P. R. Nanga, J. R. Brender, J. Xu, K. Hartman, V. Subramanian, and A. Ramamoorthy, "Three-dimensional structure and orientation of rat islet amyloid polypeptide protein in a membrane environment by solution NMR spectroscopy," Journal of the American Chemical Society, vol. 131, no. 23, pp. 8252-8261, 2009.

[54] S. M. Patil, S. Xu, S. R. Sheftic, and A. T. Alexandrescu, "Dynamic $\alpha$-helix structure of micelle-bound human amylin," Journal of Biological Chemistry, vol. 284, no. 18, pp. 11982-11991, 2009.

[55] M. Apostolidou, S. A. Jayasinghe, and R. Langen, "Structure of $\alpha$-helical membrane-bound human islet amyloid polypeptide and its implications for membrane-mediated misfolding," Journal of Biological Chemistry, vol. 283, no. 25, pp. 17205-17210, 2008.

[56] S. A. Jayasinghe and R. Langen, "Membrane interaction of islet amyloid polypeptide," Biochimica et Biophysica ActaBiomembranes, vol. 1768, no. 8, pp. 2002-2009, 2007.

[57] J. R. Brender, D. L. Heyl, S. Samisetti et al., "Membrane disordering is not sufficient for membrane permeabilization by islet amyloid polypeptide: studies of IAPP(20-29) fragments," 
Physical Chemistry Chemical Physics, vol. 15, no. 23, pp. 89088915, 2013.

[58] M. F. M. Sciacca, J. R. Brender, D.-K. Lee, and A. Ramamoorthy, "Phosphatidylethanolamine enhances amyloid fiber-dependent membrane fragmentation," Biochemistry, vol. 51, no. 39, pp. 7676-7684, 2012.

[59] R. P. R. Nanga, J. R. Brender, S. Vivekanandan, and A. Ramamoorthy, "Structure and membrane orientation of IAPP in its natively amidated form at physiological $\mathrm{pH}$ in a membrane environment," Biochimica et Biophysica Acta-Biomembranes, vol. 1808, no. 10, pp. 2337-2342, 2011.

[60] J. R. Brender, J. Krishnamoorthy, G. M. L. Messina et al., "Zinc stabilization of prefibrillar oligomers of human islet amyloid polypeptide," Chemical Communications, vol. 49, no. 32, pp. 3339-3341, 2013.

[61] J. R. Brender, E. L. Lee, K. Hartman et al., "Biphasic effects of insulin on islet amyloid polypeptide membrane disruption," Biophysical Journal, vol. 100, no. 3, pp. 685-692, 2011.

[62] A. Abedini and D. P. Raleigh, "The role of His-18 in amyloid formation by human islet amyloid polypeptide," Biochemistry, vol. 44, no. 49, pp. 16284-16291, 2005.

[63] S. Jha, J. M. Snell, S. R. Sheftic et al., "PH dependence of amylin fibrillization," Biochemistry, vol. 53, no. 2, pp. 300-310, 2014.

[64] G. Pappalardo, D. Milardi, A. Magrì et al., "Environmental factors differently affect human and rat IAPP: conformational preferences and membrane interactions of IAPP17-29 peptide derivatives," Chemistry, vol. 13, no. 36, pp. 10204-10215, 2007.

[65] K. Yanagi, M. Ashizaki, H. Yagi, K. Sakurai, Y. H. Lee, and Y. Goto, "Hexafluoroisopropanol induces amyloid fibrils of islet amyloid polypeptide by enhancing both hydrophobic and electrostatic interactions," The Journal of Biological Chemistry, vol. 286, no. 27, pp. 23959-23966, 2011.

[66] S. B. P. Chargé, E. J. P. de Koning, and A. Clark, "Effect of pH and insulin on fibrillogenesis of islet amyloid polypeptide in vitro," Biochemistry, vol. 34, no. 44, pp. 14588-14593, 1995.

[67] A. Mazzaglia, N. Micali, L. M. Scolaro et al., "Aggregation properties of the peptide fragments derived from the 17-29 region of the human and rat IAPP: a comparative study with two PEG-conjugated variants of the human sequence," Journal of Physical Chemistry B, vol. 114, no. 2, pp. 705-713, 2010.

[68] J. R. Brender, K. Hartman, R. P. R. Nanga et al., "Role of zinc in human islet amyloid polypeptide aggregation," Journal of the American Chemical Society, vol. 132, no. 26, pp. 8973-8983, 2010.

[69] E. D. Harris, "Copper transport: an overview," Proceedings of the Society for Experimental Biology and Medicine, vol. 196, no. 2, pp. 130-140, 1991.

[70] J. Mayes, C. Tinker-Mill, O. Kolosov, H. Zhang, B. J. Tabner, and D. J. Allsop, “ $\beta$-amyloid fibrils in Alzheimer disease are not inert when bound to copper ions but can degrade hydrogen peroxide and generate reactive oxygen species," The Journal of Biological Chemistry, vol. 289, no. 17, pp. 12052-12062, 2014.

[71] P. Faller, C. Hureau, and G. la Penna, "Metal ions and intrinsically disordered proteins and peptides: from $\mathrm{Cu} / \mathrm{Zn}$ amyloid- $\beta$ to general principles," Accounts of Chemical Research, vol. 47, no. 8, pp. 2252-2259, 2014.

[72] B. J. Tabner, S. Turnbull, O. M. A. El-Agnaf, and D. Allsop, "Formation of hydrogen peroxide and hydroxyl radicals from $\mathrm{A} \beta$ and $\alpha$-synuclein as a possible mechanism of cell death in Alzheimer's disease and Parkinson's disease," Free Radical Biology and Medicine, vol. 32, no. 11, pp. 1076-1083, 2002.
[73] N. R. Williams, J. Rajput-Williams, J. A. West, S. V. Nigdikar, J. W. Foote, and A. N. Howard, "Plasma, granulocyte and mononuclear cell copper and zinc in patients with diabetes mellitus," The Analyst, vol. 120, no. 3, pp. 887-890, 1995.

[74] J. W. Eaton and M. Qian, "Interactions of copper with glycated proteins: possible involvement in the etiology of diabetic neuropathy," Molecular and Cellular Biochemistry, vol. 234-235, no. 1-2, pp. 135-142, 2002.

[75] A. Masad, L. Hayes, B. J. Tabner et al., "Copper-mediated formation of hydrogen peroxide from the amylin peptide: a novel mechanism for degeneration of islet cells in type-2 diabetes mellitus?” FEBS Letters, vol. 581, no. 18, pp. 3489-3493, 2007.

[76] A. Masad, B. J. Tabner, J. Mayes, and D. Allsop, “The amylin peptide implicated in type 2 diabetes stimulates copper-mediated carbonyl group and ascorbate radical formation," Free Radical Biology and Medicine, vol. 51, no. 4, pp. 869-875, 2011.

[77] B. J. Tabner, O. M. A. El-Agnaf, S. Turnbull et al., "Hydrogen peroxide is generated during the very early stages of aggregation of the amyloid peptides implicated in Alzheimer disease and familial British dementia," Journal of Biological Chemistry, vol. 280, no. 43, pp. 35789-35792, 2005.

[78] L. Ma, X. Li, Y. Wang, W. Zheng, and T. Chen, "Cu(II) inhibits hIAPP fibrillation and promotes hIAPP-induced beta cell apoptosis through induction of ROS-mediated mitochondrial dysfunction," Journal of Inorganic Biochemistry, vol. 140, pp. 143-152, 2014.

[79] K. A. Jellinger, "The relevance of metals in the pathophysiology of neurodegeneration, pathological considerations," International Review of Neurobiology, vol. 110, pp. 1-47, 2013.

[80] M. P. Cuajungco, C. J. Frederickson, and A. I. Bush, "Amyloidbeta metal interaction and metal chelation," Sub-Cellular Biochemistry, vol. 38, pp. 235-254, 2005.

[81] E. C. Lee, E. Ha, S. Singh et al., "Copper(II)-human amylin complex protects pancreatic cells from amylin toxicity," Physical Chemistry Chemical Physics, vol. 15, no. 30, pp. 12558-12571, 2013.

[82] B. Ward, K. Walker, and C. Exley, "Copper(II) inhibits the formation of amylin amyloid in vitro," Journal of Inorganic Biochemistry, vol. 102, no. 2, pp. 371-375, 2008.

[83] Y. P. Yu, P. Lei, J. Hu, W. H. Wu, Y. F. Zhao, and Y. M. Li, “Copperinduced cytotoxicity: reactive oxygen species or islet amyloid polypeptide oligomer formation," Chemical Communications, vol. 46, no. 37, pp. 6909-6911, 2010.

[84] A. Sinopoli, A. Magrì, D. Milardi et al., "The role of copper(II) in the aggregation of human amylin," Metallomics, vol. 6, no. 10, pp. 1841-1852, 2014.

[85] C. Kállay, Á. Dávid, S. Timári et al., "Copper(II) complexes of rat amylin fragments," Dalton Transactions, vol. 40, no. 38, pp. 9711-9721, 2011.

[86] M. C. Foster, R. D. Leapman, M. X. Li, and I. Atwater, "Elemental composition of secretory granules in pancreatic islets of Langerhans," Biophysical Journal, vol. 64, no. 2, pp. 525-532, 1993.

[87] A. B. Chausmer, "Zinc, insulin, and diabetes," Journal of the American College of Nutrition, vol. 17, no. 2, pp. 109-115, 1998.

[88] P. Westermark, Z.-C. Li, G. T. Westermark, A. Leckström, and D. F. Steiner, "Effects of beta cell granule components on human islet amyloid polypeptide fibril formation," FEBS Letters, vol. 379, no. 3, pp. 203-206, 1996.

[89] S. Salamekh, J. R. Brender, S.-J. Hyung et al., "A two-site mechanism for the inhibition of IAPP amyloidogenesis by zinc," Journal of Molecular Biology, vol. 410, no. 2, pp. 294-306, 2011. 
[90] C. G. Taylor, "Zinc, the pancreas, and diabetes: insights from rodent studies and future directions," BioMetals, vol. 18, no. 4, pp. 305-312, 2005.

[91] G. Dodson and D. Steiner, "The role of assembly in insulin's biosynthesis," Current Opinion in Structural Biology, vol. 8, no. 2, pp. 189-194, 1998.

[92] X. F. Huang and P. Arvan, "Intracellular transport of proinsulin in pancreatic beta-cells. Structural maturation probed bydisulfide accessibility," Journal of Biological Chemistry, vol. 270, no. 35, pp. 20417-20423, 1995.

[93] K. Lemaire, M. A. Ravier, A. Schraenen et al., "Insulin crystallization depends on zinc transporter ZnT8 expression, but is not required for normal glucose homeostasis in mice," Proceedings of the National Academy of Sciences of the United States of America, vol. 106, no. 35, pp. 14872-14877, 2009.

[94] J. Janson, W. C. Soeller, P. C. Roche et al., "Spontaneous diabetes mellitus in transgenic mice expressing human islet amyloid polypeptide," Proceedings of the National Academy of Sciences of the United States of America, vol. 93, no. 14, pp. 7283-7288, 1996.

[95] A. Lorenzo, B. Razzaboni, G. C. Weir, and B. A. Yankner, "Pancreatic islet cell toxicity of amylin associated with type-2 diabetes mellitus," Nature, vol. 368, no. 6473, pp. 756-760, 1994.

[96] S. E. Kahn, S. Andrikopoulos, and C. B. Verchere, "Islet amyloid: a long-recognized but underappreciated pathological feature of type 2 diabetes," Diabetes, vol. 48, no. 2, pp. 241-253, 1999.

[97] A. E. Butler, J. Janson, W. C. Soeller, and P. C. Butler, "Increased $\beta$-cell apoptosis prevents adaptive increase in $\beta$-cell mass in mouse model of type 2 diabetes: Evidence for role of islet amyloid formation rather than direct action of amyloid," Diabetes, vol. 52, no. 9, pp. 2304-2314, 2003.

[98] B. Konarkowska, J. F. Aitken, J. Kistler, S. Zhang, and G. J. S. Cooper, "The aggregation potential of human amylin determines its cytotoxicity towards islet $\beta$-cells," FEBS Journal, vol. 273, no. 15, pp. 3614-3624, 2006.

[99] G. Acocella, "Clinical pharmacokinetics of rifampicin," Clinical Pharmacokinetics, vol. 3, no. 2, pp. 108-127, 1978.

[100] G. Bates, "Huntingtin aggregation and toxicity in Huntington's disease," The Lancet, vol. 361, no. 9369, pp. 1642-1644, 2003.

[101] J. J. Meier, R. Kayed, C.-Y. Lin et al., "Inhibition of human IAPP fibril formation does not prevent $\beta$-cell death: evidence for distinct actions of oligomers and fibrils of human IAPP," The American Journal of Physiology-Endocrinology and Metabolism, vol. 291, no. 6, pp. E1317-E1324, 2006.

[102] C. G. Glabe and R. Kayed, "Common structure and toxic function of amyloid oligomers implies a common mechanism of pathogenesis," Neurology, vol. 66, no. 2, supplement 1, pp. S74S78, 2006.

[103] S. E. Lesné, M. A. Sherman, M. Grant et al., "Brain amyloid- $\beta$ oligomers in ageing and Alzheimer's disease," Brain, vol. 136, no. 5, pp. 1383-1398, 2013.

[104] Y. Bram, A. Frydman-Marom, I. Yanai et al., "Apoptosis induced by islet amyloid polypeptide soluble oligomers is neutralized by diabetes-associated specific antibodies," Scientific Reports, vol. 4, article 4267, 2014.

[105] H.-L. Zhao, Y. Sui, J. Guan et al., "Amyloid oligomers in diabetic and nondiabetic human pancreas," Translational Research, vol. 153, no. 1, pp. 24-32, 2009.

[106] R. A. Ritzel, J. J. Meier, C.-Y. Lin, J. D. Veldhuis, and P. C. Butler, "Human islet amyloid polypeptide oligomers disrupt cell coupling, induce apoptosis, and impair insulin secretion in isolated human islets," Diabetes, vol. 56, no. 1, pp. 65-71, 2007.
[107] S. P. Zhang, J. X. Liu, M. Dragunow, and G. J. S. Cooper, "Fibrillogenic amylin evokes islet $\beta$-cell apoptosis through linked activation of a caspase cascade and JNK1," The Journal of Biological Chemistry, vol. 278, no. 52, pp. 52810-52819, 2003.

[108] S. P. Zhang, J. X. Liu, E. L. Saafi, and G. J. S. Cooper, "Induction of apoptosis by human amylin in RINm5F islet $\beta$-cells is associated with enhanced expression of p53 and p21(WAF1/CIP1)," FEBS Letters, vol. 455, no. 3, pp. 315-320, 1999.

[109] M. Couce, L. A. Kane, T. D. O’Brien et al., “Treatment with growth hormone and dexamethasone in mice transgenic for human islet amyloid polypeptide causes islet amyloidosis and $\beta$-cell dysfunction," Diabetes, vol. 45, no. 8, pp. 1094-1101, 1996.

[110] C. B. Verchere, D. A. D’Alessio, R. D. Palmiter et al., "Islet amyloid formation associated with hyperglycemia in transgenic mice with pancreatic beta cell expression of human islet amyloid polypeptide," Proceedings of the National Academy of Sciences of the United States of America, vol. 93, no. 8, pp. 3492-3496, 1996.

[111] T. Gurlo, S. Ryazantsev, C.-J. Huang et al., "Evidence for proteotoxicity in $\beta$ cells in type 2 diabetes: toxic islet amyloid polypeptide oligomers form intracellularly in the secretory pathway," The American Journal of Pathology, vol. 176, no. 2, pp. 861-869, 2010.

[112] C.-Y. Lin, T. Gurlo, R. Kayed et al., “Toxic human islet amyloid polypeptide (h-IAPP) oligomers are intracellular, and vaccination to induce anti-toxic oligomer antibodies does not prevent h-IAPP-induced $\beta$-cell apoptosis in h-IAPP transgenic mice," Diabetes, vol. 56, no. 5, pp. 1324-1332, 2007.

[113] C.-J. Huang, L. Haataja, T. Gurlo et al., "Induction of endoplasmic reticulum stress-induced $\beta$-cell apoptosis and accumulation of polyubiquitinated proteins by human islet amyloid polypeptide," The American Journal of Physiology-Endocrinology and Metabolism, vol. 293, no. 6, pp. E1656-E1662, 2007.

[114] L. Khemtémourian, J. A. Killian, J. W. Höppener, and M. F. M. Engel, "Recent insights in islet amyloid polypeptide-induced membrane disruption and its role in beta-cell death in type 2 diabetes mellitus," Experimental Diabetes Research, vol. 2008, Article ID 421287, 9 pages, 2008.

[115] P. Westermark, "Fine structure of islets of langerhans in insular amyloidosis," Virchows Archiv A, vol. 359, no. 1, pp. 1-18, 1973.

[116] E. L. Saafi, B. Konarkowska, S. Zhang, J. Kistler, and G. J. S. Cooper, "Ultrastructural evidence that apoptosis is the mechanism by which human amylin evokes death in RINm5F pancreatic islet $\beta$-cells," Cell Biology International, vol. 25 , no. 4 , pp. 339-350, 2001.

[117] M. Anguiano, R. J. Nowak, and P. T. Lansbury Jr., "Protofibrillar islet amyloid polypeptide permeabilizes synthetic vesicles by a pore-like mechanism that may be relevant to type II diabetes," Biochemistry, vol. 41, no. 38, pp. 11338-11343, 2002.

[118] J. Janson, R. H. Ashley, D. Harrison, S. McIntyre, and P. C. Butler, "The mechanism of islet amyloid polypeptide toxicity is membrane disruption by intermediate-sized toxic amyloid particles," Diabetes, vol. 48, no. 3, pp. 491-498, 1999.

[119] Y. Porat, S. Kolusheva, R. Jelinek, and E. Gazit, "The human islet amyloid polypeptide forms transient membrane-active prefibrillar assemblies," Biochemistry, vol. 42, no. 37, pp. 1097110977, 2003.

[120] R. Kayed, Y. Sokolov, B. Edmonds et al., "Permeabilization of lipid bilayers is a common conformation-dependent activity of soluble amyloid oligomers in protein misfolding diseases," The Journal of Biological Chemistry, vol. 279, no. 45, pp. 4636346366, 2004. 
[121] R. Kayed, J. Bernhagen, N. Greenfield et al., "Conformational transitions of islet amyloid polypeptide (IAPP) in amyloid formation in vitro," Journal of Molecular Biology, vol. 287, no. 4, pp. 781-796, 1999.

[122] S. Gilead, H. Wolfenson, and E. Gazit, "Molecular mapping of the recognition interface between the islet amyloid polypeptide and insulin," Angewandte Chemie-International Edition, vol. 45, no. 39, pp. 6476-6480, 2006.

[123] E. T. A. S. Jaikaran, M. R. Nilsson, and A. Clark, "Pancreatic $\beta$-cell granule peptides form heteromolecular complexes which inhibit islet amyloid polypeptide fibril formation," Biochemical Journal, vol. 377, no. 3, pp. 709-716, 2004.

[124] I. Rustenbeck, A. Matthies, and S. Lenzen, "Lipid composition of glucose-stimulated pancreatic islets and insulin-secreting tumor cells," Lipids, vol. 29, no. 10, pp. 685-692, 1994.

[125] S. A. Jayasinghe and R. Langen, "Lipid membranes modulate the structure of islet amyloid polypeptide," Biochemistry, vol. 44, no. 36, pp. 12113-12119, 2005.

[126] J. D. Knight and A. D. Miranker, "Phospholipid catalysis of diabetic amyloid assembly," Journal of Molecular Biology, vol. 341, no. 5, pp. 1175-1187, 2004.

[127] J. D. Knight, J. A. Hebda, and A. D. Miranker, "Conserved and cooperative assembly of membrane-bound $\alpha$-helical states of islet amyloid polypeptide," Biochemistry, vol. 45, no. 31, pp. 9496-9508, 2006.

[128] E. Sparr, M. F. M. Engel, D. V. Sakharov et al., "Islet amyloid polypeptide-induced membrane leakage involves uptake of lipids by forming amyloid fibers," FEBS Letters, vol. 577, no. 12, pp. 117-120, 2004.

[129] T. Konno, S. Oiki, and T. Morii, "Synergistic action of polyanionic and non-polar cofactors in fibrillation of human islet amyloid polypeptide," FEBS Letters, vol. 581, no. 8, pp. 16351638, 2007.

[130] A. M. Ruschak and A. D. Miranker, "Fiber-dependent amyloid formation as catalysis of an existing reaction pathway," Proceedings of the National Academy of Sciences of the United States of America, vol. 104, no. 30, pp. 12341-12346, 2007.

[131] S. Jha, S. M. Patil, J. Gibson, C. E. Nelson, N. N. Alder, and A. T. Alexandrescu, "Mechanism of amylin fibrillization enhancement by heparin," The Journal of Biological Chemistry, vol. 286, no. 26, pp. 22894-22904, 2011.

[132] M. Wogulis, S. Wright, D. Cunningham, T. Chilcote, K. Powell, and R. E. Rydel, "Nucleation-dependent polymerization is an essential component of amyloid-mediated neuronal cell death," Journal of Neuroscience, vol. 25, no. 5, pp. 1071-1080, 2005.

[133] M. Kawahara, Y. Kuroda, N. Arispe, and E. Rojas, "Alzheimer's $\beta$-amyloid, human islet amylin, and prion protein fragment evoke intracellular free calcium elevations by a common mechanism in a hypothalamic GnRH neuronal cell lin," The Journal of Biological Chemistry, vol. 275, no. 19, pp. 14077-14083, 2000.

[134] M. P. Mattson, B. Cheng, D. Davis, K. Bryant, I. Lieberburg, and R. E. Rydel, " $\beta$-Amyloid peptides destabilize calcium homeostasis and render human cortical neurons vulnerable to excitotoxicity," Journal of Neuroscience, vol. 12, no. 2, pp. 376389, 1992.

[135] M. F. M. Sciacca, D. Milardi, G. M. L. Messina et al., "Cations as switches of amyloid-mediated membrane disruption mechanisms: calcium and IAPP," Biophysical Journal, vol. 104, no. 1, pp. 173-184, 2013.

[136] P. Gilon, H. Y. Chae, G. A. Rutter, and M. A. Ravier, "Calcium signaling in pancreatic $\beta$-cells in health and in Type 2 diabetes," Cell Calcium, vol. 56, no. 5, pp. 340-361, 2014.
[137] M. Salas, R. A. Silvestre, O. Garcia-Hermida, T. Fontela, J. Rodriguez-Gallardo, and J. Marco, "Inhibitory effect of amylin (islet amyloid polypeptide) on insulin response to non-glucose stimuli. Study in perfused rat pancreas," Diabete et Metabolisme, vol. 21, no. 4, pp. 269-273, 1995.

[138] H. Ohsawa, A. Kanatsuka, T. Yamaguchi, H. Makino, and S. Yoshida, "Islet amyloid polypeptide inhibits glucose-stimulated insulin secretion from isolated rat pancreatic islets," Biochemical and Biophysical Research Communications, vol. 160, no. 2, pp. 961-967, 1989.

[139] T. Zhu, Y. Wang, B. He, J. Zang, Q. He, and W. Zhang, "Islet amyloid polypeptide acts on glucose-stimulated beta cells to reduce voltage-gated calcium channel activation, intracellular $\mathrm{Ca}^{2+}$ concentration, and insulin secretion," Diabetes/Metabolism Research and Reviews, vol. 27, no. 1, pp. 28-34, 2011.

[140] M. Soty, M. Visa, S. Soriano, M. D. C. Carmona, Á. Nadal, and A. Novials, "Involvement of ATP-sensitive potassium (K ATP) channels in the loss of beta-cell function induced by human islet amyloid polypeptide," The Journal of Biological Chemistry, vol. 286, no. 47, pp. 40857-40866, 2011.

[141] B. J. Blanchard, A. Chen, L. M. Rozeboom, K. A. Stafford, P. Weigele, and V. M. Ingram, "Efficient reversal of Alzheimer's disease fibril formation and elimination of neurotoxicity by a small molecule," Proceedings of the National Academy of Sciences of the United States of America, vol. 101, no. 40, pp. 14326-14332, 2004.

[142] S. Casas, R. Gomis, F. M. Gribble, J. Altirriba, S. Knuutila, and A. Novials, "Impairment of the ubiquitin-proteasome pathway is a downstream endoplasmic reticulum stress response induced by extracellular human islet amyloid polypeptide and contributes to pancreatic beta-cell apoptosis," Diabetes, vol. 56, no. 9, pp. 2284-2294, 2007.

[143] R. L. Hull, S. Zraika, J. Udayasankar, K. Aston-Mourney, S. L. Subramanian, and S. E. Kahn, "Amyloid formation in human IAPP transgenic mouse islets and pancreas, and human pancreas, is not associated with endoplasmic reticulum stress," Diabetologia, vol. 52, no. 6, pp. 1102-1111, 2009.

[144] D. Scheuner and R. J. Kaufman, "The unfolded protein response: a pathway that links insulin demand with $\beta$-cell failure and diabetes," Endocrine Reviews, vol. 29, no. 3, pp. 317-333, 2008.

[145] Y. C. Kudva, C. Mueske, P. C. Butler, and N. L. Eberhardt, "A novel assay in vitro of human islet amyloid polypeptide amyloidogenesis and effects of insulin secretory vesicle peptides on amyloid formation," Biochemical Journal, vol. 331, part 3, pp. 809-813, 1998.

[146] Y. Ishida, A. Yamamoto, A. Kitamura et al., "Autophagic elimination of misfolded procollagen aggregates in the endoplasmic reticulum as a means of cell protection," Molecular Biology of the Cell, vol. 20, no. 11, pp. 2744-2754, 2009.

[147] V. Kirkin, D. G. McEwan, I. Novak, and I. Dikic, "A role for ubiquitin in selective autophagy," Molecular Cell, vol. 34, no. 3, pp. 259-269, 2009.

[148] N. Mizushima and M. Komatsu, "Autophagy: renovation of cells and tissues," Cell, vol. 147, no. 4, pp. 728-741, 2011.

[149] W. H. Yu, A. M. Cuervo, A. Kumar et al., "Macroautophagya novel $\beta$-amyloid peptide-generating pathway activated in Alzheimer's disease," Journal of Cell Biology, vol. 171, no. 1, pp. 87-98, 2005.

[150] J. Kim, H. Cheon, Y. T. Jeong et al., "Amyloidogenic peptide oligomer accumulation in autophagy-deficient $\beta$ cells induces 
diabetes," The Journal of Clinical Investigation, vol. 124, no. 8, pp. 3311-3324, 2014.

[151] N. Shigihara, A. Fukunaka, A. Hara et al., "Human IAPPinduced pancreatic $\beta$ cell toxicity and its regulation by autophagy," Journal of Clinical Investigation, vol. 124, no. 8, pp. 3634-3644, 2014.

[152] M. Stefani and C. M. Dobson, "Protein aggregation and aggregate toxicity: new insights into protein folding, misfolding diseases and biological evolution," Journal of Molecular Medicine, vol. 81, no. 11, pp. 678-699, 2003.

[153] J. D. Acharya and S. S. Ghaskadbi, "Islets and their antioxidant defense," Islets, vol. 2, no. 4, pp. 225-235, 2010.

[154] S. Zraika, R. L. Hull, J. Udayasankar et al., "Oxidative stress is induced by islet amyloid formation and time-dependently mediates amyloid-induced beta cell apoptosis," Diabetologia, vol. 52, no. 4, pp. 626-635, 2009.

[155] S. L. Subramanian, R. L. Hull, S. Zraika, K. Aston-Mourney, J. Udayasankar, and S. E. Kahn, "cJUN N-terminal kinase (JNK) activation mediates islet amyloid-induced beta cell apoptosis in cultured human islet amyloid polypeptide transgenic mouse islets," Diabetologia, vol. 55, no. 1, pp. 166-174, 2012.

[156] E. S. Levitan, "Signaling for vesicle mobilization and synaptic plasticity," Molecular Neurobiology, vol. 37, no. 1, pp. 39-43, 2008.

[157] P. Maechler and C. B. Wollheim, "Mitochondrial function in normal and diabetic $\beta$-cells," Nature, vol. 414, no. 6865, pp. 807812, 2001.

[158] G. E. Gibson, S. S. Karuppagounder, and Q. Shi, "Oxidantinduced changes in mitochondria and calcium dynamics in the pathophysiology of Alzheimer's disease," Annals of the New York Academy of Sciences, vol. 1147, pp. 221-232, 2008.

[159] Y.-A. Lim, V. Rhein, G. Baysang et al., "A $\beta$ and human amylin share a common toxicity pathway via mitochondrial dysfunction," Proteomics, vol. 10, no. 8, pp. 1621-1633, 2010.

[160] P. Li, D. Nijhawan, I. Budihardjo et al., "Cytochrome c and dATP-dependent formation of Apaf-1/caspase-9 complex initiates an apoptotic protease cascade," Cell, vol. 91, no. 4, pp. 479489, 1997.

[161] P. Gubellini, B. Picconi, M. di Filippo, and P. Calabresi, "Downstream mechanisms triggered by mitochondrial dysfunction in the basal ganglia: from experimental models to neurodegenerative diseases," Biochimica et Biophysica Acta-Molecular Basis of Disease, vol. 1802, no. 1, pp. 151-161, 2010.

[162] S. Zhang, J. Liu, G. MacGibbon, M. Dragunow, and G. J. S. Cooper, "Increased expression and activation of c-Jun contributes to human amylin-induced apoptosis in pancreatic islet $\beta$-cells," Journal of Molecular Biology, vol. 324, no. 2, pp. 271-285, 2002.

[163] K. Maedler, G. A. Spinas, R. Lehmann et al., "Glucose induces $\beta$-cell apoptosis via upregulation of the Fas receptor in human islets," Diabetes, vol. 50, no. 8, pp. 1683-1690, 2001.

[164] S. Zhang, H. Liu, H. Yu, and G. J. S. Cooper, "Fas-associated death receptor signaling evoked by human amylin in islet betacells," Diabetes, vol. 57, no. 2, pp. 348-356, 2008.

[165] N. G. N. Milton and J. R. Harris, "Fibril formation and toxicity of the non-amyloidogenic rat amylin peptide," Micron, vol. 44, no. 1, pp. 246-253, 2013.

[166] A. Nath, A. D. Miranker, and E. Rhoades, "A membrane-bound antiparallel dimer of rat islet amyloid polypeptide," Angewandte Chemie, vol. 50, no. 46, pp. 10859-10862, 2011.
[167] I. Sebastião, E. Candeias, M. S. Santos C, P. I. Moreira, and A. I. Duarte, "Insulin as a bridge between typer 2 diabets and Alzheimer disease-how antidiabetics could be a solution for dementia," Frontiers in Endocrinology, vol. 5, article 110, pp. 1-13, 2014.

[168] Y. Yang and W. Song, "Molecular links between Alzheimer's disease and diabetes mellitus," Neuroscience, vol. 250, pp. 140150, 2013.

[169] L.-M. Yan, A. Velkova, and A. Kapurniotu, "Molecular characterization of the hetero-assembly of $\beta$-amyloid peptide with islet amyloid polypeptide," Current Pharmaceutical Design, vol. 20, no. 8, pp. 1182-1191, 2014.

[170] C. E. Higham, E. T. A. S. Jaikaran, P. E. Fraser, M. Gross, and A. Clark, "Preparation of synthetic human islet amyloid polypeptide (IAPP) in a stable conformation to enable study of conversion to amyloid-like fibrils," FEBS Letters, vol. 470, no. 1, pp. 55-60, 2000.

[171] J. R. Brender, E. L. Lee, M. A. Cavitt, A. Gafni, D. G. Steel, and A. Ramamoorthy, "Amyloid fiber formation and membrane disruption are separate processes localized in two distinct regions of IAPP, the type-2-diabetes-related peptide," Journal of the American Chemical Society, vol. 130, no. 20, pp. 6424-6429, 2008.

[172] S. Jha, D. Sellin, R. Seidel, and R. Winter, "Amyloidogenic propensities and conformational properties of ProIAPP and IAPP in the presence of lipid bilayer membranes," Journal of Molecular Biology, vol. 389, no. 5, pp. 907-920, 2009.

[173] A. Demuro, E. Mina, R. Kayed, S. C. Milton, I. Parker, and C. G. Glabe, "Calcium dysregulation and membrane disruption as a ubiquitous neurotoxic mechanism of soluble amyloid oligomers," Journal of Biological Chemistry, vol. 280, no. 17, pp. 17294-17300, 2005.

[174] S. A. Kotler, P. Walsh, J. R. Brender, and A. Ramamoorthy, "Differences between amyloid- $\beta$ aggregation in solution and on the membrane: insights into elucidation of the mechanistic details of Alzheimer's disease," Chemical Society Reviews, vol. 43, no. 19, pp. 6692-6700, 2014.

[175] B. O'Nuallain, A. D. Williams, P. Westermark, and R. Wetzel, "'seeding specificity in amyloid growth induced by heterologous fibrils," The Journal of Biological Chemistry, vol. 279, no. 17, pp. 17490-17499, 2004.

[176] R. Kayed, E. Head, J. L. Thompson et al., "Common structure of soluble amyloid oligomers implies common mechanism of pathogenesis," Science, vol. 300, no. 5618, pp. 486-489, 2003.

[177] G. Grasso, M. L. Giuffrida, and E. Rizzarelli, "Metallostasis and amyloid $\beta$-degrading enzymes," Metallomics, vol. 4, no. 9, pp. 937-949, 2012.

[178] F. Bellia and G. Grasso, "The role of copper(II) and zinc(II) in the degradation of human and murine IAPP by insulindegrading enzyme," Journal of Mass Spectrometry, vol. 49, no. 4, pp. 274-279, 2014.

[179] W. Q. Qiu and M. F. Folstein, "Insulin, insulin-degrading enzyme and amyloid- $\beta$ peptide in Alzheimer's disease: review and hypothesis," Neurobiology of Aging, vol. 27, no. 2, pp. 190198, 2006.

[180] S. Ayton, P. Lei, and A. I. Bush, "Metallostasis in Alzheimer's disease," Free Radical Biology and Medicine, vol. 62, pp. 76-89, 2013.

[181] P. Faller, C. Hureau, and O. Berthoumieu, "Role of metal ions in the self-assembly of the Alzheimer's amyloid- $\beta$ peptide," Inorganic Chemistry, vol. 52, no. 21, pp. 12193-12206, 2013. 
[182] G. Arena, G. Pappalardo, I. Sovago, and E. Rizzarelli, "Copper(II) interaction with amyloid- $\beta$ : affinity and speciation," Coordination Chemistry Reviews, vol. 256, no. 1-2, pp. 3-12, 2012.

[183] A. I. Bush, "The metallobiology of Alzheimer's disease," Trends in Neurosciences, vol. 26, no. 4, pp. 207-214, 2003.

[184] A. Gnjec, J. A. Fonte, C. Atwood, and R. N. Martins, “Transition metal chelator therapy-a potential treatment for Alzheimer's disease?" Frontiers in Bioscience, vol. 7, pp. 1016-1023, 2002.

[185] Z. Kroner, "The relationship between Alzheimer's disease and diabetes: type 3 diabetes?” Alternative Medicine Review, vol. 14, no. 4, pp. 373-379, 2009.

[186] L. Li and C. Hölscher, "Common pathological processes in Alzheimer disease and type 2 diabetes: a review," Brain Research Reviews, vol. 56, no. 2, pp. 384-402, 2007.

[187] G. S. Desai, C. Zheng, T. Geetha et al., "The pancreas-brain axis: insight into disrupted mechanisms associating type 2 diabetes and Alzheimer's disease," Journal of Alzheimer's Disease, vol. 42, no. 2, pp. 347-356, 2014.

[188] K. Jackson, G. A. Barisone, E. Diaz, L.-W. Jin, C. DeCarli, and F. Despa, "Amylin deposition in the brain: a second amyloid in Alzheimer disease?" Annals of Neurology, vol. 74, no. 4, pp. 517526, 2013.

[189] M. L. Giuffrida, F. Tomasello, F. Caraci, S. Chiechio, F. Nicoletti, and A. Copani, "Beta-Amyloid monomer and insulin/IGF-1 signaling in Alzheimer's disease," Molecular Neurobiology, vol. 46, no. 3, pp. 605-613, 2012.

[190] M. L. Giuffrida, F. Caraci, B. Pignataro et al., "Beta-amyloid monomers are neuroprotective," Journal of Neuroscience, vol. 29, no. 34, pp. 10582-10587, 2009.

[191] B. L. Adler, M. Yarchoan, H. M. Hwang et al., "Neuroprotective effects of the amylin analogue pramlintide on Alzheimer's disease pathogenesis and cognition," Neurobiology of Aging, vol. 35, no. 4, pp. 793-801, 2014.

[192] W. Q. Qiu and H. Zhu, "Amylin and its analogs: a friend or foe for the treatment of Alzheimer's disease?" Frontiers in Aging Neuroscience, vol. 6, article 186, 9 pages, 2014.

[193] E. Andreetto, L.-M. Yan, A. Caporale, and A. Kapurniotu, "Dissecting the role of single regions of an IAPP mimic and IAPP in inhibition of A $\beta 40$ amyloid formation and cytotoxicity," ChemBioChem, vol. 12, no. 9, pp. 1313-1322, 2011.

[194] J. Seeliger, F. Evers, C. Jeworrek et al., "Cross-amyloid interaction of A $\beta$ and IAPP at lipid membranes," Angewandte Chemie, vol. 51, no. 3, pp. 679-683, 2012.

[195] N. Rezaei-Ghaleh, E. Andreetto, L.-M. Yan, A. Kapurniotu, M. Zweckstetter, and J. Santos, "Interaction between amyloid beta peptide and an aggregation blocker peptide mimicking islet amyloid polipeptide," PLoS ONE, vol. 6, no. 5, Article ID e20289, 2011. 


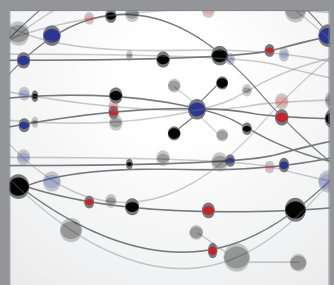

The Scientific World Journal
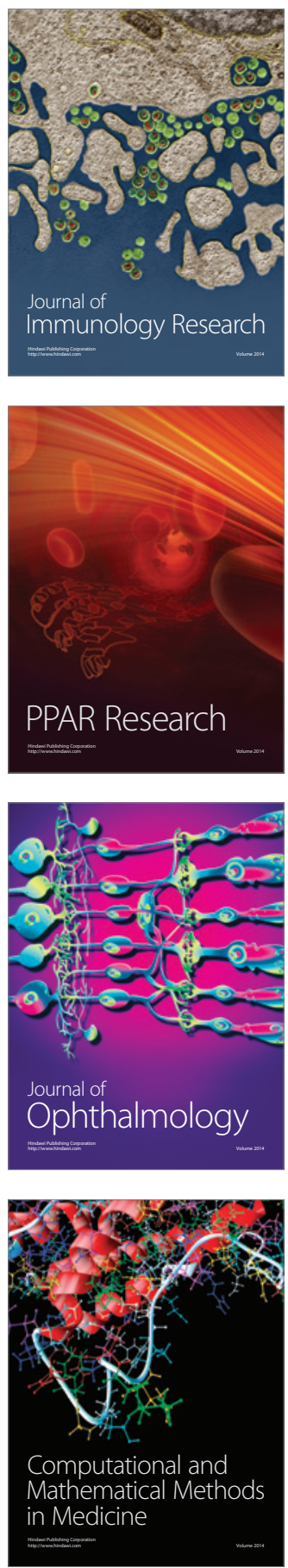

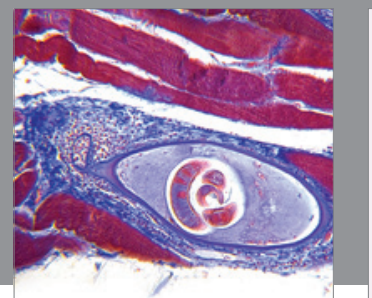

Gastroenterology

Research and Practice
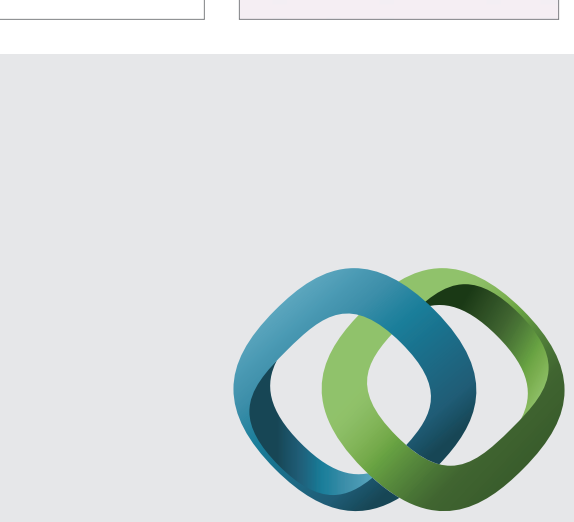

\section{Hindawi}

Submit your manuscripts at

http://www.hindawi.com
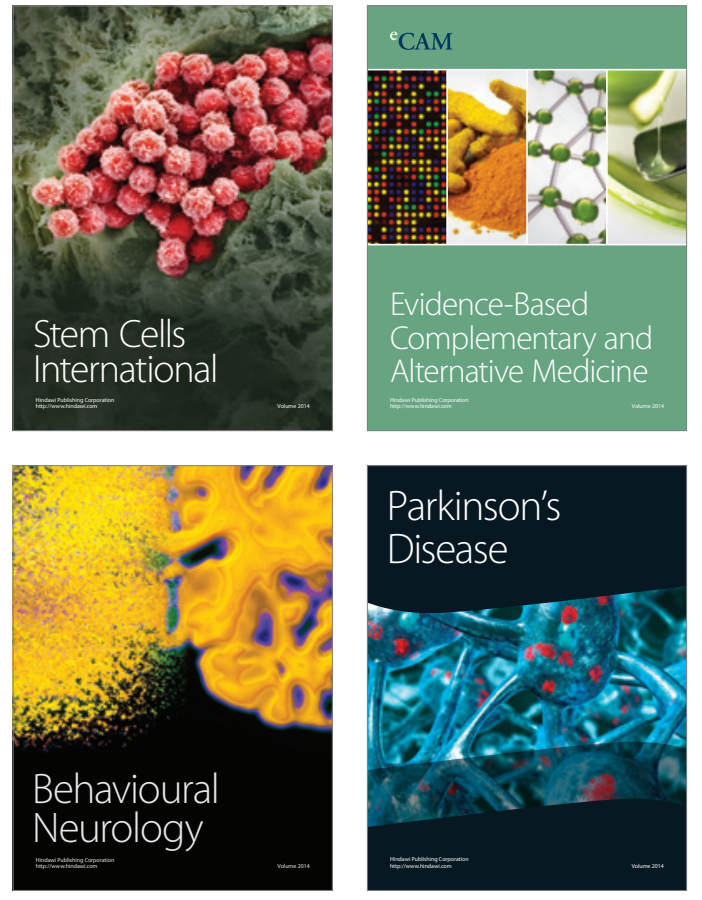
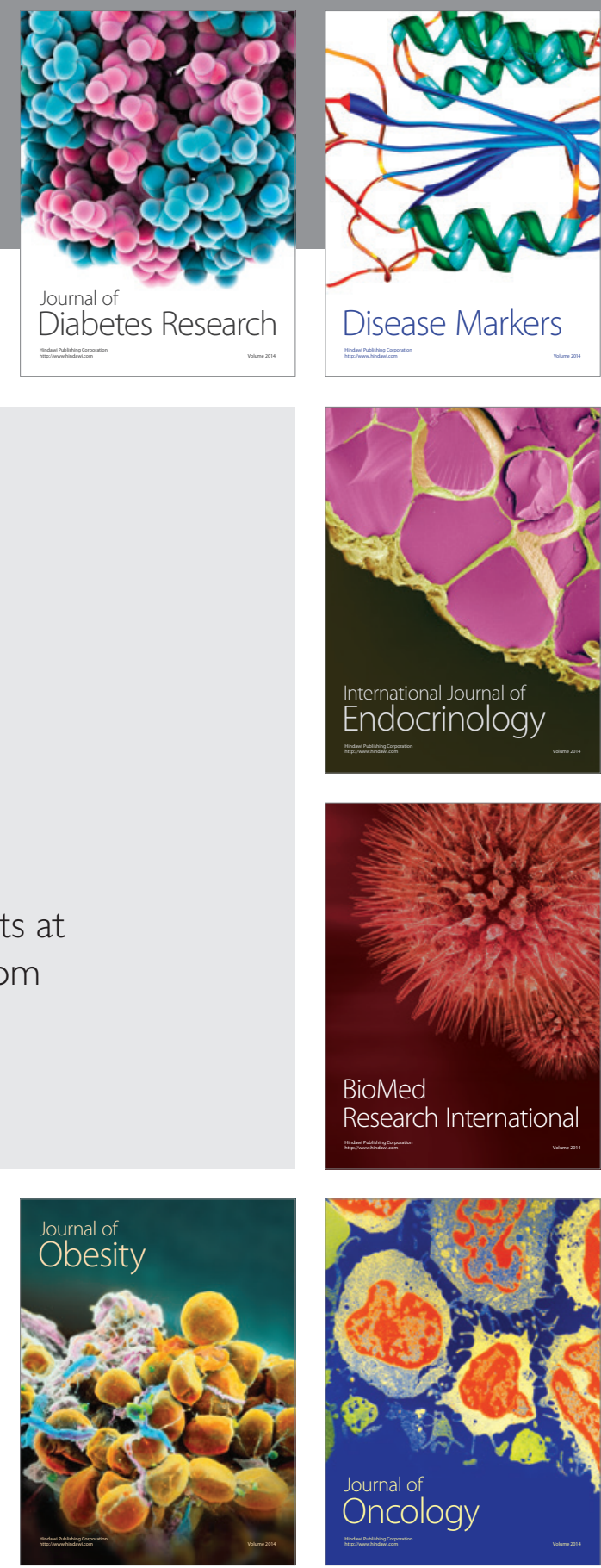

Disease Markers
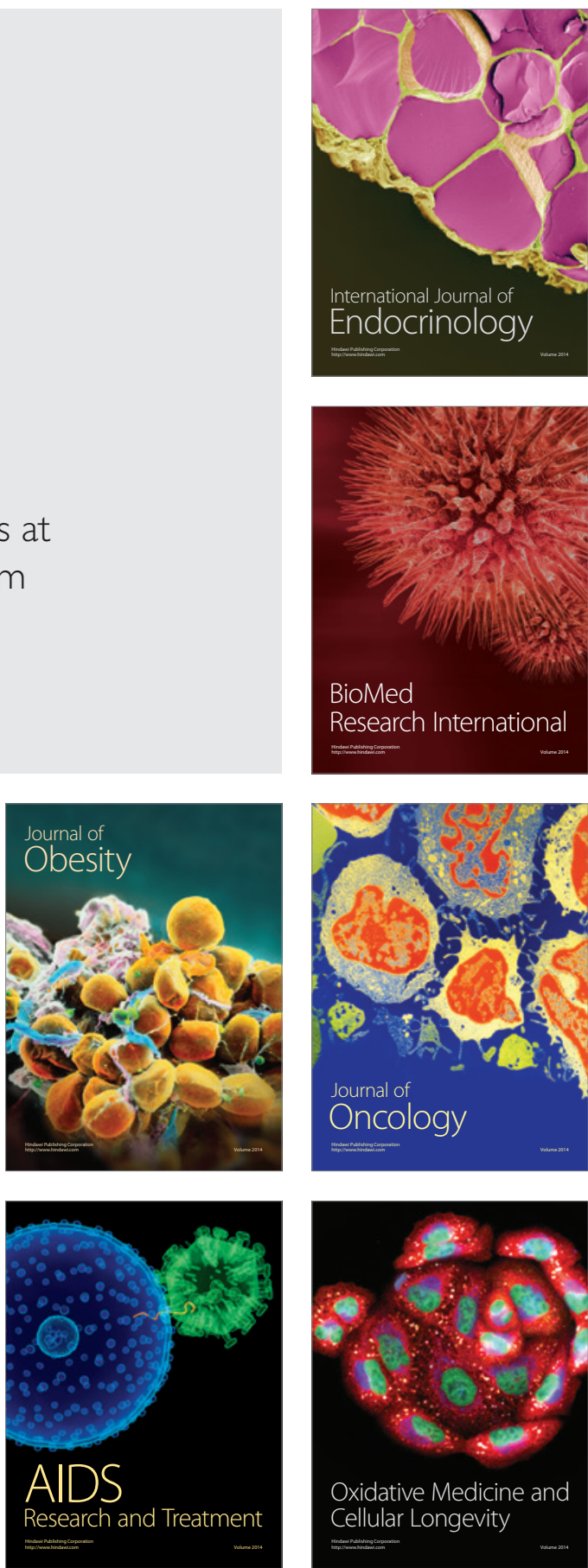